\title{
The Effect of Occlusal Pressure on Vertical Force Generation on Dentate and Edentulous Subjects
}

\author{
Matthew Thomas Harper \\ WVU School of Dentistry, mharper4@mix.wvu.edu
}

Follow this and additional works at: https://researchrepository.wvu.edu/etd

Part of the Prosthodontics and Prosthodontology Commons

\section{Recommended Citation}

Harper, Matthew Thomas, "The Effect of Occlusal Pressure on Vertical Force Generation on Dentate and Edentulous Subjects" (2019). Graduate Theses, Dissertations, and Problem Reports. 3817.

https://researchrepository.wvu.edu/etd/3817

This Thesis is protected by copyright and/or related rights. It has been brought to you by the The Research Repository @ WVU with permission from the rights-holder(s). You are free to use this Thesis in any way that is permitted by the copyright and related rights legislation that applies to your use. For other uses you must obtain permission from the rights-holder(s) directly, unless additional rights are indicated by a Creative Commons license in the record and/ or on the work itself. This Thesis has been accepted for inclusion in WVU Graduate Theses, Dissertations, and Problem Reports collection by an authorized administrator of The Research Repository @ WVU. For more information, please contact researchrepository@mail.wvu.edu. 
The Effect of Occlusal Pressure on Vertical Force Generation on Dentate and Edentulous Subjects

Matthew T Harper, D.D.S.

Thesis submitted to the

School of Dentistry

At West Virginia University

In Partial fulfillment of the requirements

For the degree of

Master of Science

In

Prosthodontics

\author{
Matthew S. Bryington, D.M.D., M.S. (Chair) \\ Jean McCrory, PhD. \\ Bryan Weaver, D.D.S., M.D
}

Department of Restorative Dentistry

Morgantown, West Virginia

2019

Keywords: Jump Analysis, Edentulous, Implant Overdenture, Force Plate Copyright 2019 Matthew T Harper 


\begin{abstract}
The Effect of Occlusal Pressure on Vertical Force Generation on Dentate and Edentulous

Subjects

Matthew Thomas Harper, D.D.S.
\end{abstract}

Objectives: To determine 1) the difference in lower extremity power obtained from a vertical jump in individuals who are dentate or edentulous (implants or dentures) and 2) the difference occlusal pressure makes on lower body force output. Variables included jump height, maximum kicking force, maximum push off force, take off velocity, flight time, jump impulse, and maximum velocity. Groups included dentate, implant overdenture, and conventional denture. Methods: Counter movement jumping with force plate collection was utilized to test the three populations in this study. The three populations were dentate, mandibular implant overdenture opposing maxillary complete denture, and conventional maxillary and mandibular complete dentures. The dentate group was asked to clench their teeth at the beginning and throughout the counter movement jump. The edentulous groups were asked to clench with their prostheses in and to relax with them out.

Results: The force variables tested showed significant differences between the three test groups. Maximum velocity was only showed significant between the dentate in comparison to the other two groups, but not between implant or conventional. There was found to be no significant difference between the force variables and occlusal pressure.

Conclusions: In the present study, there was a significant difference found between the three dental condition groups of edentulous, implant, and dentate. The results indicate that the oral rehabilitation method did impact lower body force generation in all of the variables, with the exception of maximum velocity which only showed significance between edentulous and dentate. 


\section{Acknowledgements}

I would like to thank the following for their guidance and contributions:

Dr. Matthew Bryington - I am grateful for your instruction with this project, and with providing me with the freedom to pursue something that at the time sounded farfetched.

Dr. Nicole Andreini - I would like to thank you for reading my chapters as I finished them, for providing me insight when I had writer's block, and for ensuring me that everything was happening right on time.

Dr's Mike Evans and Ben Kordusky - I would like to thank you both for helping support me these last few months in completing my writing.

Lyndsey Gray - I would like to thank you for helping run all of the Axium reports to collect our participant pool, for going through them all to filter out positive and negative selections, and for providing me encouragement.

Dr. Desiree Harper - I would like to thank you for proof reading my chapters, for encouraging me when I felt discouraged, and for providing me valuable ideas for my writing.

Dr. George Harper - I would like to thank you for helping me construct and transport the landing platform.

James and Jordan- I would like to thank you both for helping run my computer protocols, compiling the data, running the data, and assisting me with other essential parts of the project.

Dr. Jean McCrory - I am very grateful for your mentorship throughout this process. For all the chapters read, to the continued support when I felt discouraged, and to writing the custom programs to acquire and process our data. 


\section{Table Of Contents}

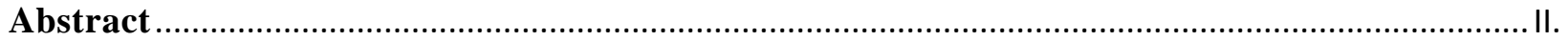

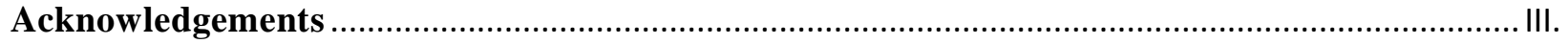

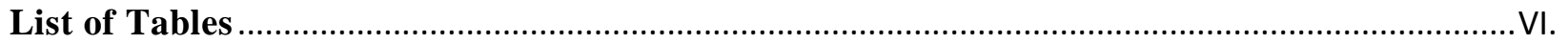

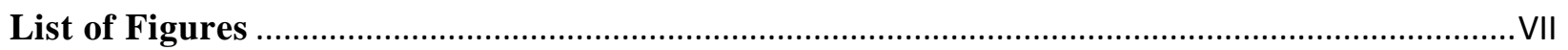

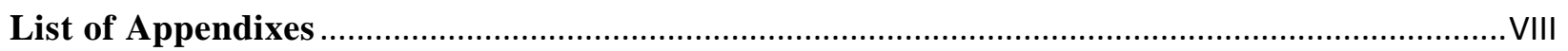

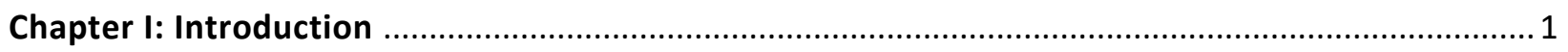

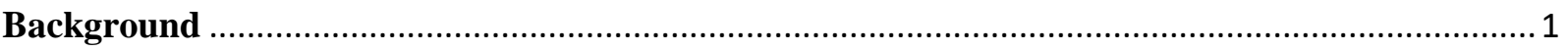

Significance of the Problem ......................................................................................................

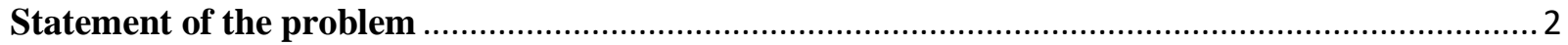

Hypotheses …

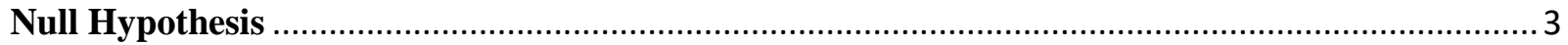

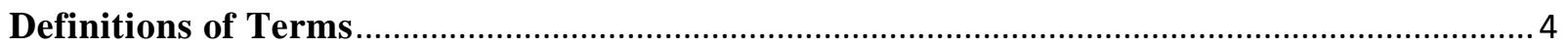

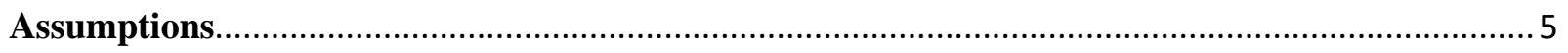

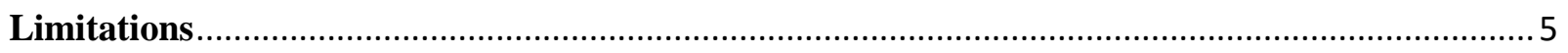

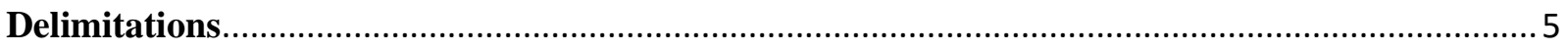

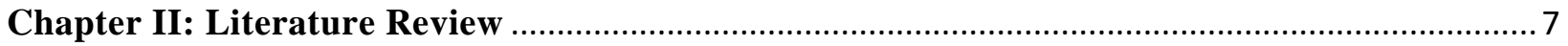

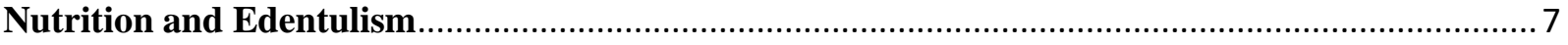

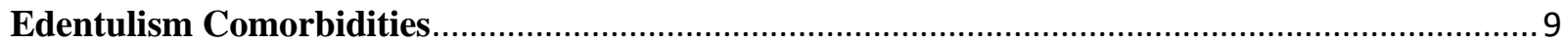

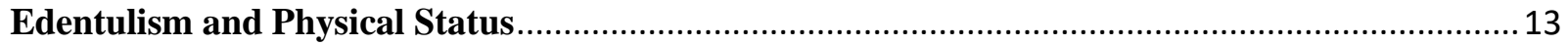

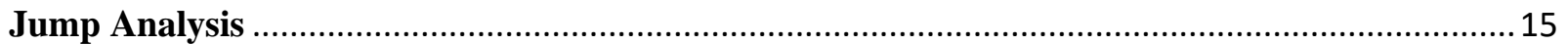

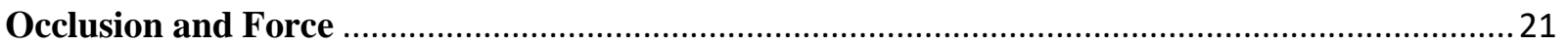

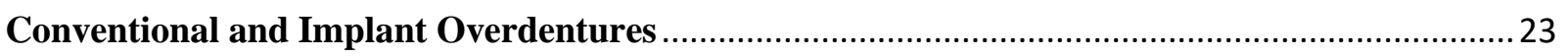

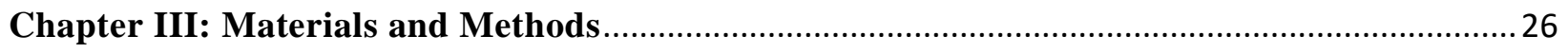

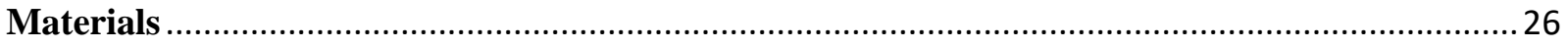

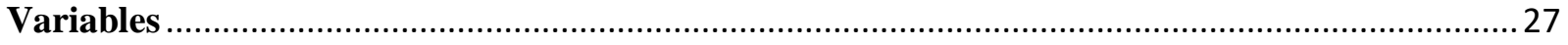

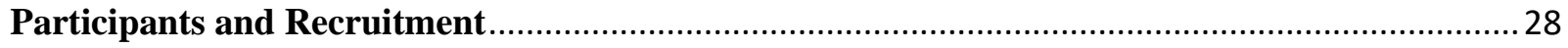

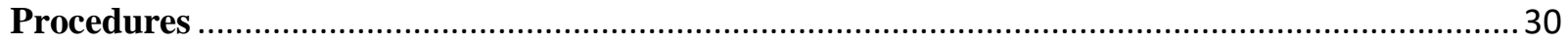

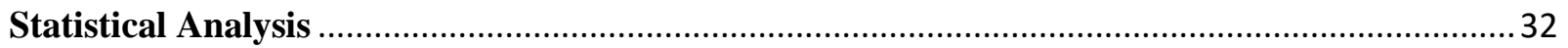

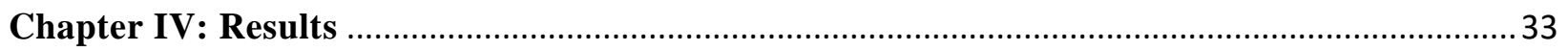

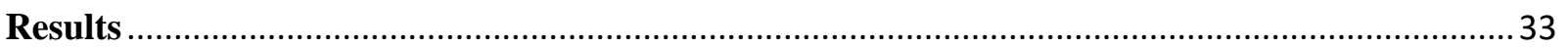

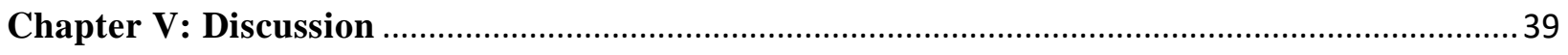

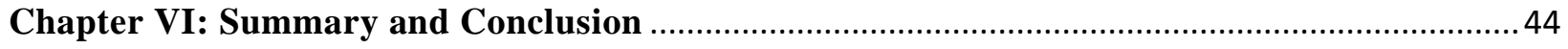


Summary.

Conclusion 44

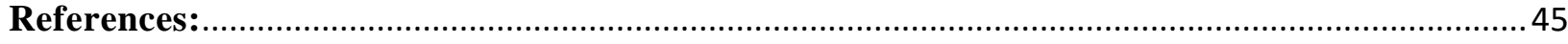

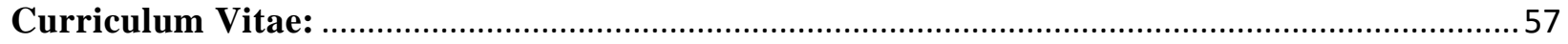

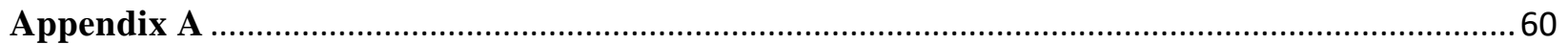

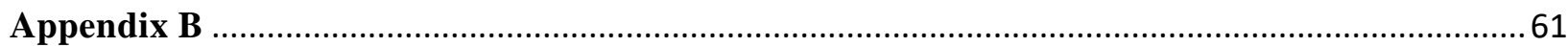




\section{List of Tables}

Table 1. Demographics

Table 2. Demographics Group Significance

Table 3. Flight Time

Table 4. Jump Height

Table 5. Take Off Velocity

Table 6. Maximum Kicking Force

Table 7. Maximum Push Off

Table 8. Jump Impulse

Table 9. Maximum Velocity 


\section{List of Figures}

Figure 1. Ground reaction forces during a counter-movement jump. 


\section{List of Appendixes}

Appendix A. Recruitment Statement

Appendix B. Informed Consent 


\section{Chapter I: Introduction}

\section{Background}

A great deal of research has been conducted to elucidate co-morbidities associated with edentulism. Current statistics show that edentulism rates are decreasing over time, but with the increase in population, the total number of people becoming edentulous is growing(Slade, Akinkugbe, \& Sanders, 2014). Many different modalities have been utilized to restore individuals that are edentulous. The traditional modality is a tissue-supported acrylic prosthetic, a conventional denture(Nowjack-Raymer \& Sheiham, 2003). With the introduction of endosteal dental implants, clinicians are able to fabricate prostheses that are retained and supported in part or fully by dental implants(Thomason, Kelly, Bendkowski, \& Ellis, 2012).

Research has indicated that the use of dental implants allows for the patient to have an increased quality of life in regards to their dental condition(Nascimento et al., 2017). Enhanced rates of chewing efficiency, perceived phonetic benefit, and improved psychosocial qualities have been noted(Assunção, Barão, Delben, Gomes, \& Tabata, 2010; Nascimento et al., 2017). Very little research has been conducted on the holistic benefits of implant therapy, specifically lower limb force generation.

It is well known that, on average, as we age, decreases in activity level, decreases in muscle mass, and loss of bone mineral density can be noted. These conditions frequently lead to injury, with hip fractures being a major concern in our elderly population(Greenspan et al., n.d.). Until recently, no connection has been made between tooth loss and injury rates. Furthermore, reasoning behind this connection has not been fully elucidated in the literature. Differences between dentate and edentulous individuals, as well as implant retained versus conventional dentures yet to be determined in regards to lower limb force development. 


\section{Significance of the Problem}

Many understood comorbidities accompany the loss of one's teeth. The impact of implants on the quality of life of edentulous individuals and the change in these comorbidities have been elucidated. Currently, little knowledge is presented on the impact loss of teeth has on one's overall physical capabilities. Understanding the impact this has on one's ability to generate force, specifically in the lower body, can help clinicians better understand ways to positively influence patients quality of life as they age. This study focused on the differences between force generation with and without occlusal pressure. It further assessed variable oral situations: fully dentate, maxillary complete denture opposing mandibular complete denture, and maxillary complete denture opposing two-implant mandibular overdenture.

\section{Statement of the problem}

The research intended to explore the degree to which occlusal stability and occlusal pressure effect lower body force production. Additionally, the impact of the presence or absence of teeth or implants on lower body force generation will be assessed.

Specific Aim 1: To examine the effect of occlusal pressure (high vs low) on lower extremity force during take-off of a counter-movement jump.

Specific Aim 2: To examine the effect of dental condition (dentate, implants, and conventional dentures) on lower extremity force during take off of a counter-movement jump.

\section{Hypotheses}

Hypothesis 1: Effect of occlusal stability: Participants with greater occlusal stability (dentate subjects) will have a greater difference between the test conditions in relation to their 
force variables than will participants with less occlusal stability (subjects in conventional dentures).

Hypothesis 2: Effect of occlusal pressure: The magnitude of the force variables will be larger in the high occlusal pressure condition than in the lower occlusal pressure condition.

\section{Null Hypothesis}

There will be no difference in the variables of force with or without occlusal pressure.

There will be no difference in force variables in relation to occlusal stability. 


\section{Definitions of Terms}

Abutment $=$ the portion of the dental implant that serves to support and/or retain a prosthesis

Centric relation $=$ the maxillomandibular relationship in which the condyles articulate with the thinnest avascular portion of their respective disks, with the complex in the anteriorsuperior position against the slopes of the articular eminencies.

Conventional denture $=$ removable dental prosthesis that replaces the entire dentition and associated structures of the maxilla or mandible.

Countermovement Jump $=$ common test used in research to measure jumping ability. Begins in the standing position and involves a rapid countermovement until the knees reach 90 degrees, whereby the movement is explosively reversed.

Dentate/Dentulous $=$ a condition in which natural teeth are present in the mouth

Edentulous $=$ without teeth/lacking teeth

Force Plate $=$ force platforms or force plates are measuring instruments that measure the ground reaction forces generated by a body standing on or moving across them, to quantify balance, gait, and other parameters of biomechanics

Implant $=$ a device placed into the alveolar and/or basal bone of the mandible or maxillae and transecting only one cortical plate; the endosteal dental implant is composed of an anchorage component, termed the endosteal dental implant, which, ideally, is within the bone

Implant overdenture $=$ implant supported removable prosthesis

Locator $=$ specific abutment utilized for the retention of a removable implant overdenture

Mandible $=$ the lower jawbone 
Maxilla $=$ the irregularly shaped bone that, with its contralateral maxilla, forms the upper jaw. Assists in the formation of the orbit, the nasal cavity, and the hard palate; it contains the maxillary teeth

Maximum intercuspation $=$ Complete intercuspation of the opposing teeth independent of condylar position, sometimes referred to as the best fit of the teeth regardless of the condylar position

Occlusal pressure $=$ any force exerted on the occlusal surfaces of teeth

Occlusal stability $=$ the equalization of contacts that prevents tooth movement

\section{Assumptions}

1. It is assumed that individuals are producing an equally maximum jump in every trial.

2. It is assumed that footwear had no effect on findings. The footwear worn by the subjects was consistent between high and low occlusal pressure conditions within each subject.

3. It is assumed that each edentulous patient was restored into centric relation.

4. It is assumed that each dentate patient was clenching into maximum intercuspation.

5. It is assumed the Locator inserts were properly retaining the overdentures.

\section{Limitations}

1. Sample size of 9 implant overdentures and 5 conventional dentures for edentulous statistical analysis.

2. We investigated limited methods of oral rehabilitation.

3. We were only able to record one occlusal situation per patient (conventional denture, implant overdenture, dentate)

\section{Delimitations}

1. This study is limited to conventional denture, implant overdenture, or dentate individuals.

2. This study is limited to only a two implant, locator abutment system for non-conventional complete dentures. 
3. This study is limited to only mandibular overdentures. 


\section{Chapter II: Literature Review}

\section{Nutrition and Edentulism}

The rate at which tooth loss is decreasing in the United States has improved, but the amount of edentulous individuals is not insignificant. An estimated 12.5 million over the age of 25 report having a complete denture prosthesis(Felton, 2009; Slade et al., 2014). Even with the fabrication of conventional dentures by a dental professional, an edentulous individual can only generate only a fraction of the masticatory force that a dentate individual can(Chauncey, Muench, Kapur, \& Wayler, 1984). Tooth loss is the most frequent cause for a deficiency in mastication(Felton, 2009). The actual amount varies on an individual basis, and is greatly influenced by having a quality prosthesis.

Support, retention, and stability are all important factors to consider about the prosthesis. Despite having a quality prosthesis generated for them, many patients report-chewing problems (Nowjack-Raymer \& Sheiham, 2003). These chewing problems can include decreased chewing efficiency, change in diet away from foods that were previously enjoyed due to inability to consume them, and alteration in food taste(Nowjack-Raymer \& Sheiham, 2003).

Masticatory efficiency studies are conducting by having subjects masticate a test food followed by sieving to particle size of the remaining food. Either food or artificial substitutes are used in these studies, with artificial substitutes being preferred so there is no bias introduced by the choice of food(Elsyad \& Khairallah, 2017). With the loss of teeth, there is a loss of proprioception. Edentulous individuals lack a majority of their proprioception in their mouth, and therefore can have issues fully masticating particles. Research indicates that various digestive problems can manifest when swallowing of larger food particles occurs frequently(N'Gom \& Woda, 2002). Reduced chewing ability has been linked to overall reduction in general health and functional capacity. As adults age, they tend to use more strokes 
and chew longer to adequately prepare food for swallowing and digestion(Sheiham, Steele, Marcenes, Finch, \& Walls, 1999). However, chewing ability appears to be more closely associated with dental status rather than age. Studies are in disagreement on whether prosthetic rehabilitation with conventional dentures alone result in a significant improvement in dietary status and quality.

Clinical studies have shown that providing individuals with prostheses alone does not remove the nutritional deficits that accompany tooth loss. The absence of a functioning and harmonious masticatory system has been linked to an alarming amount of health issues. Many of these health issues stem from the nutritional deficits an edentulous individual should expect to encounter. The inability to generate masticatory force directly correlates to one's ability to masticate food. Consuming a diet rich in vegetables, fiber, and variable sources of protein is important for keeping overall health. Joshipura et al. showed that as participants lost teeth over time, the intake of nutritious foods declined (Joshipura, Willett, \& Douglass, 1996). In addition, it has been shown that denture wearers consumed less vegetables and whole meal bread(Nowjack-Raymer \& Sheiham, 2003). The lower consumption of quality whole grain carbohydrates lead to lower levels of fiber consumption. Denture wearers also were shown to consume leafy greens and carrots up to 2 times less than dentate individuals did(Papas, Palmer, Rounds, \& Russell, 1998). This lack of quality carbohydrates and leafy greens leaves the edentulous individual at a severe nutritional disadvantage. Fruit consumption was not shown to drastically change, but choice of fruit did. Individuals in this study were less likely to have hard fruits such as apples and pears. A study by Corby et al. suggested that denture wearers were also less likely to consume fruits, have lower levels of calcium, carotene, and protein(Corby et al., 2018). There lies a correlation between lower amounts of food energy coming from protein 
sources and being an edentulous elderly individual. Elderly dentate individuals are more likely to consume higher levels of protein packed foods. A connection between having lower amounts of energy supplied by protein than did dentate elderly. Edentulous individuals also had higher levels of cholesterol and saturated fat than the dentate did(Corby et al., 2018). Ultimately, edentulous individuals were more likely to have weight increases of greater than $5 \%$ of their body weight in a year than a dentate group was(Corby et al., 2018).

The problem of nutritional deficiency is indeed multifactorial. Factors included are general health, socioeconomic status, psychological health, and dietary status. Oral health status is an important factor when considering nutritional and dietary status.

\section{Edentulism Comorbidities}

The complete loss of teeth, or edentulism, is the terminal outcome of many biologic processes. Dental caries, periodontal disease, pulpal pathology, trauma, and oral pathology can all lead to the loss of teeth over time. Many of these factors are chronic oral diseases, which represents a large health care burden throughout the world, and in many areas without established healthcare systems it becomes quickly neglected. Statistics show that the incidence of edentulism is between 7 and 69\% internationally(Polzer, Schimmel, Müller, \& Biffar, 2010). A study conducted in 2010, Oral health-Healthy People, showed that approximately $25 \%$ of the US population between the ages of 65 and 74 are edentulous. This patient population is at higher risks for diseases due to their age, but this risk is compounded by the fact they are edentulous.

The impact oral health has on overall health creates a large financial burden on both the patient and the system as a whole(Felton, 2009). Dimensioned oral health and edentulism has been associated with many life threatening conditions, diseases, and deficits. The World Health Organization (WHO) classifies individuals with no teeth as physically impaired(Felton, 2009). 
These patients can further be classified as disabled due to inability to effectively eat and speak(Verbrugge \& Jette, 1994). These are considered two essential tasks of life, and the avoidance of or inability to do these things in public highlights the negative impact it has on their lives.

Osteoporosis is a major concern for many individuals as they age. The decrease in bone mineral density increases the odds of severe fractures, falls, and typically causes individuals to become even more sedentary(Ensrud et al., 2009; Greenspan et al., n.d.). At this time, there is only weak evidence to list edentulism as a risk factor for osteoporosis. Of interest a recent study has shown a correlation between tooth loss and hip fractures(Koka, Priebe, Wermers, Sems, \& Viozzi, 2017). For every five teeth that were missing, after adjusting for age, individuals had a $26 \%$ increased chance of undergoing a hip fracture. In the hip fracture group, $34 \%$ of the individuals were missing twenty or more teeth, compared to only $12 \%$ in the non-fracture group(Koka et al., 2017). Evidence indicates that keeping natural teeth or replacing them with prostheses is associated with fewer falls and frailty among elderly. Frailty has been associated with increased risk of falls, hip fractures, and overall mortality. Fabricating a prosthesis for an individual lacking posterior occlusion has been suggested to decrease fall risk(Kimura et al., 2013). The one-year morality rate following an osteoporotic hip fracture has been reported to range between 9\% and 36\%(Taylor et al., 2004). Several factors associate with this statistic, chiefly age, male sex, and a delay in surgery from injury. Dental status was not evaluated in this previous study but others have. Fracture risk assessment score, or FRAX, is a WHO tool to assess osteoporotic fracture risk. Koka et al. showed a positive correlation with the overall FRAX probability that one will have an osteoporotic fracture within 10 years and the number of missing teeth(Koka et al., 2017). This significance corroborates a study by Greenspan et al. that 
showed an association between missing 20 or more teeth and osteoporotic hip fracture(Greenspan et al., n.d.). While more research needs to be conducted to elucidate the correlation between these, it is an area of concern.

According to the Center for Disease Control, every 43 seconds someone in the United States dies from something related to cardiovascular disease(CDC, 2017). Coronary artery disease has been linked to both the biologic reasons for tooth loss, such as periodontal disease and tooth decay, and to edentulism(Hung et al., 2004). Edentulous patients carry more than two times the risk plaque formation in the carotid artery than individuals missing less than nine teeth(Heitmann \& Gamborg, 2008). Schwahn et al. investigated the connection between periodontal disease, complete edentulism, and levels of plasma fibrinogen(Schwahn et al., 2004). Increased levels of plasma fibrinogen is a known marker for inflammation and has a connection to cardiovascular disease(Schwahn et al., 2004). The study concluded that there was an almost two-fold increase in the levels of plasma fibrinogen in partially edentulous patients suffering from periodontal disease. While there would be less inflammation in the edentulous patient than in the partially edentulous periodontal involved patient, the process of losing one's teeth can involve periodontal disease. Another connection to heart disease for the edentulous population has to do with the prostheses dental professionals provide them. A study by Ajwani et al. showed that edentulous individuals recorded higher intraoral microbial counts than their dentate counterparts did(Ajwani, Mattila, Närhi, Tilvis, \& Ainamo, 2003). With higher microbial counts, which can lead to inflammation, microbial aspiration, and higher blood bacterial counts, there is cause for concern in relation to overall health(Ajwani et al., 2003).

Bacterial aspiration is a concern for individuals who do not adequately remove or clean their dentures, and this can lead to aspiration pneumonia. Higher blood bacterial counts can lead 
to general inflammation for the body, linking to plasma fibrinogen and other blood markers(Sheiham et al., 2001). Hämäläinen et al. showed that edentulism associated significantly with poor baseline and decreases at a five year follow up for Forced Expiratory Volume (FEV)(Hämäläinen, Suominen, Keskinen, \& Meurman, 2004). This is the amount of air that can be expired after a deep breath, and is associated with pulmonary function(Hämäläinen, Suominen, et al., 2004). Lower levels of FEV correlate to decreases in performance and physical ability. Periodontitis was also associated with this decrease in FEV(Hämäläinen, Rantanen, Keskinen, \& Meurman, 2004). Studies have indicated that deep periodontal pockets are reservoirs of bacteria, which can be particularly harmful for the elderly(Hämäläinen, Suominen, et al., 2004; Meurman, Pajukoski, Snellman, Zeiler, \& Sulkava, 1997; Schwahn et al., 2004).

Edentulous individuals to have almost a two-fold increase in their risk for diabetes than dentate counterparts. Uncontrolled diabetes is associated with a host of health related issues associated with it, including diminished healing capacity, cardiovascular disease, vision loss, limb loss, and decrease in functional capacity. It has been indicated that functionally edentulous men were at four times greater risk for developing non-insulin dependent diabetes(Felton, 2009).

One of the most apparent changes for individuals after complete tooth loss is the intraoral anatomical changes that they undergo. The alveolar tissue is present to support the teeth; following tooth loss the alveolar bone undergoes dramatic changes. The term residual ridge resorption has been used to describe the alveolar ridge that remains post extraction(Atwood, 1971). The quality and quantity of both the hard and soft tissues change(Atwood, 1971). This change leads to issues with stability and retention of a future prosthesis, which affects the patient's ability to function. The mandibular residual ridge is shown to have bone resorption at four times the rate of the maxilla(Atwood, 1971). The mandibular complete denture is typically 
not as tolerated in comparison to the maxillary complete denture, and this only serves to further this problem. Factors influencing residual ridge resorption are classified as local and systemic. Local factors are the length of time an individual has been edentulous, the initial size of the resulting alveolar ridge, amount of pressure that is transmitted through the removable prosthesis, a history of either complete or partial dentures, and refusing to remove the denture at night(Atwood, 1971). Systemic factors can include age, gender, smoking, and to a lesser extent calcium intake, osteoporosis, asthma, and obesity(Felton, 2009).

As stated, edentulism has been linked to an increased risk for systemic chronic disease and death(Brown, 2009). This increased risk of morality may be linked to the fact that tooth loss may be an underlying factor that is associated with death risk, including socioeconomic factors, infection, inflammation, and behavior(Brown, 2009). Edentulous individuals under the age of 65 have a risk of death from all causes of $19 \%$, while their dentate counterparts have only a $10 \%$ risk. The risk of death is approximately 1.5 times greater for the edentulous under 65 than the dentate(Brown, 2009).

\section{Edentulism and Physical Status}

Physical status is an important factor to consider in the elderly population. Although many noninstitutionalized elderly adults are functionally competent, the percentage who need assistance doubles every decade up to the age of 84 , and triples between the ages of 84 and 95(Nagi, 1976). A study of an institutionalized elderly population compared mortality and physical activity between edentulous individuals without complete dentures to the partially edentulous(Jette, Feldman, \& Douglass, 1993). Partially edentulous was defined as individuals with 20 or more teeth. It was shown over the six years of this study that edentulous individuals that had no complete denture, or had complete dentures that were not maintained or replaced 
experienced a decline in physical ability and had increased mortality rates. Research has indicated that oral health was correlated with independence in daily living, even though the mechanism is not fully elucidated(Rantanen et al., 2002Holm-Pedersen, Schultz-Larsen, Christiansen, \& Avlund, 2008). Some evidence shows that those with more teeth lead a more physically active life style than those with fewer teeth(Mollaoglu \& Alpar, 2005). Poor muscle strength and low levels of activity are associated with increased mortality(Rantanen et al., 2002).

Edentulism has a clear impact on the quality of life. Aside from the psychosocial, behavioral, and masticatory changes that this group of individuals has to undergo, their physical ability is also impacted(Tada, Watanabe, Yokoe, Hanada, \& Tanzawa, 2003). Tooth loss has been associated with decreases in physical strength and ability and activities of daily living(Holm-Pedersen et al., 2008; Polzer et al., 2010). A study by showed that grip strength was not statistically significant in its relationship to being edentulous(Yamaga et al., 2002). They did find that it was significantly associated with factors associated with respiration. Peak expiratory flow rate, forced expiratory volume, and force expiratory vital capacity were all found to be significantly correlated(Hämäläinen, Rantanen, et al., 2004).

Handgrip strength is a common indicator of total body strength, which is a known predictor of disability and mortality(Rantanen et al., 2003). The unadjusted analysis among men showed that a greater number of teeth had greater grip strength(Hämäläinen, Rantanen, et al., 2004). However, this association was less clear with women(Hämäläinen, Rantanen, et al., 2004). The primary result of this study showed that among 80 year old individuals, the presence of periodontitis predicted a steeper decline in handgrip strength while the number of remaining teeth had an effect on strength in the cross sectional analysis(Hämäläinen, Rantanen, et al., 2004). Previous studies have suggested that problems related to physical ability suggested that 
poor oral health has a major role in the development of disability(Avlund, Holm-Pedersen, \& Schroll, 2001; Jette et al., 1993). It was suggested that this disability is linked to decrease in muscular strength. Previous research has indicated a positive association between remaining teeth and handgrip strength(Yamaga et al., 2002). The explanation for the decrease in strength being associated with periodontitis and tooth loss may be the link to the presence of inflammation, both past and present(Hämäläinen, Rantanen, et al., 2004). Payette and Visser et al. reported that high levels of interleukin-6 and TNF-alpha both correlated with sarcopenia and poor muscle strength(Payette et al., 2003; Visser et al., 2002). Well-fitting prostheses were also correlated with improved grip strength (Hämäläinen, Rantanen, et al., 2004).

\section{Jump Analysis}

The vertical jump is widely considered the gold standard for field test of performance capability, in both trained and untrained individuals. It has been found that superior performance is due to greater muscle capability in terms of strength and rate of strength development, and not necessarily influenced by experience jumping or technique(Vanezis \& Lees, 2005). Another reason for its superiority is the fact that there is limited variability among individuals, thus making it a reliable assessment tool. Adequate warmup is sufficient to acclimate an individual to a jump protocol because it is a basic motor skill(Vanezis \& Lees, 2005). The primary challenge of a jump is to have sufficient strength in the legs to propel the body off the ground. The maximum jump an individual can execute is a strong predictor of muscular power. This height achieved can provide important information for clinicians regarding their functional capacity.

Dudley Sargent was the first to design the modern jump study protocol(Sargent, 2018). The vertical jump height was assessed as the difference between standing height and the jump height(Sargent, 2018). This method still is utilized today, but the introduction of force platforms 
has highlighted two very important performance variables, time to peak force and the rate of force development. A force platform is a rectangular metal plate, typically around $60 \mathrm{~cm} \times 50 \mathrm{~cm}$ $x 5 \mathrm{~cm}$. Either piezoelectric or strain gauge transducers attached to the corners of the internal portion of the platform. These allow an electrical output to be translated proportionally based upon the force exerted on the plate. Individuals must remain completely motionless prior to the jump phase to accurately generate the data on the force platform. If the jumper was to move prior to the jump, the ground reaction force at the start of the jump phase could not be precisely obtained in relation to the jumper's body weight. Other variables would be inaccurately calculated as well because the initial velocity of the individual would not be zero.

Utilizing Newton's laws of motion researchers are able to calculate many variables. Both portable and in ground force plates exist. The prohibitive cost of force plates and the difficulty in bringing individuals to a lab setting for in ground plates, research has been conducted to validate the reliability of portable force plates. The primary advantage of a portable plate system is that the researcher is able to bring the plate to the test subjects. The two main variables that have been shown to be better predictors of athletic performance then peak values, such as peak force and peak height(Bui, Farinas, Fortin, Comtois, \& Leone, 2015). Time to peak force and rate of force development are considered better indicators of performance due to the dynamic nature of them, they contain a time component(Eagles, Sayers, Bousson, \& Lovell, 2015).

Numerous variations have been studied; squat jumps, countermovement jumps, standing broad jump, and the absence of presence of arm swing in the movement. The counter movement vertical jump is frequently utilized in jump analysis studies. It is one of the most well studied measures of lower limb explosive strength, and is routinely used to test efficacy of strength training regimens. This is due to the fact it is closely related to most movements found within 
sports, and because it is the simplest for an untrained population to execute. The superiority of the counter movement jump over other methods becomes more apparent when the work done by the jumper is examined(Vanezis \& Lees, 2005). When utilizing this jump, the individual starts from an upright standing position. A downward movement is initiated by flexing at the knees and the hips(Vanezis \& Lees, 2005). Once reaching a certain depth, typically determined by the individual based on training history, will powerfully extend the knees and hips to jump vertically off the ground(Vanezis \& Lees, 2005). The jump must overcome their own body weight to lift off against gravity.

Other advantages of the counter movement jump become evident when analyzing the actual musculature of the legs. Therefore, the musculoskeletal system behavior of the leg can be described as a spring mass system, and the validity of this has been supported throughout the literature. This spring mass system describes how the stretching of certain muscles during the countermovement phase causes a storage and utilization of elastic energy that is released upon the change in direction. During the jumping movement the musculature of the leg must have high levels of stiffness(Wang, Lin, \& Huang, 2004). Without this high degree of stiffness, the body would not be able to apply the elastic energy that is built up effectively(Wang et al., 2004). The three main joints involved in the jumping movement are the hip, knee, and ankle. During a jump, there is an increase in stiffness of 3.4 times, 11.3 times, and 3.2 times of each joint respectively(Wang et al., 2004). These stiffness findings support the quadriceps dominant strategy of jumping that describes that the quadriceps and hamstring musculature as the primary movers in a jump. Hubley and Wells found that nearly $50 \%$ of the total positive work during a jump is at the knee, with $28 \%$ and $23 \%$ done by the hip and ankle respectively(Hubley \& Wells, 1983). As the stretch shortening cycle is completed, lift off concludes with full plantar flexion of 
the foot(Nicol, Avela, \& Komi, 2006). During the landing phase of the jump, the knee and hip extensors absorb a majority of the force acting on the body from the ground. These two sets of musculature are paramount in the prevention of injury. Once fatigue sets in, however, the forces are shifted more and more onto the hip and ankle(Rodacki, Fowler, \& Bennett, 2002). The more these two joints dominate the jump and landing phases, the more likely there is of an injury occurring.

Restriction of arm swing in the jump phase has been shown to decrease performance by up to $10 \%$ (Harman, Rosenstein, Frykman, \& Rosenstein, 1990). It is also very natural for an individual to utilize a downward arm swing during the negative knee bend phase of a counter movement jump, and to do an upward arm swing during the push off phase of the jump(Harman et al., 1990). However, this arm swing movement has been shown to increase inaccuracy and variation within power analysis(Linthorne, 2002). A vertical jump can also be performed with the hands on the hips. When this is done instead of an arm swing, the jumper's center of mass is usually a few centimeters lower than at takeoff and therefore the flight time method of analysis overestimates the true flight height by up to $2 \mathrm{~cm}$ (Kibele, 1998). This height difference is even more pronounced in the arm swing.

A force platform measures the force that an individual exerts on it. By utilizing Newton's third law of motion, researchers are also able to obtain the force exerted by the platform on the individual(Tran, Netto, Aisbett, \& Gastin, 2005). The force that is exerted onto an individual is called the ground reaction force. Ground reaction force is considered the gold standard to assess impact loading, which is the load experienced by a structure when a moving body is stopped by the structure.(Simons \& Bradshaw, 2016). This is done through the measurement of acceleration and is based on Newton's second law of motion, F=ma. In this case, 
$\mathrm{F}$ is the net force at the center of mass, $\mathrm{m}$ is the mass of the participant, and $\mathrm{a}$ is the acceleration of the center of mass of the body that is in movement. This knowledge of acceleration during the vertical displacement of the individual allows for the vertical height to be obtained(Eagles et al., 2015). Flight time is obtained from the time the individual loses contact with the platform to when they land(Eagles et al., 2015). Assuming that the time from the initiation of the jump to maximum height is equal to the time from maximum height to landing, the height of the jump can be calculated(Eagles et al., 2015). During this landing phase, it is generally assumed that both limbs will absorb the forces of landing equally. When there is a difference between force absorption between the legs, the risk for injury increases(Hewit, Cronin, \& Hume, 2012). Various factors can influence the asymmetry of force landing. Among these factors are leg dominance, injury history, and lean mass distribution between the legs(Hewit et al., 2012). The peak vertical ground reaction forces can show asymmetry between the legs, and this is related to strength and power asymmetries. These asymmetries also have high clinical relevancy for functional capacity, performance, and injury risk. Of interest, there has been shown significant differences between genders in regards to ground reaction forces, while men are shown to fatigue more quickly than women, partially due to the effects of blood flow by estrogen levels(Padua et al., 2006).

Decreases in muscular performance and increases in the risk of falling are factors of aging and are regarded as predictors of mortality. Immobility and decreases in functional capacity are multifactorial issues, but declining muscular function appears to be a key factor, and balance has been suggested to also be of great importance(Schneider, Schwab, \& Hänscheid, 2011). Functional capacity is often measured by force and power output of the lower limbs, and the tests utilized to measure these factors are considered strong predictors of fall risk(Schneider 
et al., 2011). As stated previously, peak values are not as beneficial of a measurement tool as dynamic ones, such as rate of force development. This is also true for studies regarding fall risk, as the ability to generate adequate force to catch or balance in a shorter amount of time allows an individual to better avert a fall(Guralnik, Ferrucci, Simonsick, Salive, \& Wallace, 1995). Balance, as described by Forsman et al, was the measure of the entire neuromuscular loop, and the performance that involves the cerebellum, spinal cord, muscle performance, and the innervation of the musculature(Forsman, Tietäväinen, Wallin, \& Hæggström, 2008). Another important component in this system is the boney architecture of the individual. Research indicates that muscle power and force variables obtained in vertical jump studies are predictive of bone strength(Ju et al., 2014). The vertical jump studies show greater correlation to bone strength than do other attributes such as aerobic capacity and jump height, and other testing modalities such as handgrip strength tests(Frost, 2004). Bones adapt to mechanical stress that is exerted upon them, and this mechanical stress is force(Frost, 2004). These forces occur through the movement and action of the musculature, this concept of bone and muscle being a functional unit is echoed in the strong associations found between them (Frost, 2004). Hardcastle and colleagues have shown that vertical jump peak power is associated with bone strength(Hardcastle et al., 2014). It should be noted that in respect to muscle and bone indices, peak forces are of more value than dynamic values such as time to peak force, because researchers are interested more in the force exerted on the bone. It was shown that the peak force has a strong and positive correlation with bone strength variables, such as bone mineral density(Fonseca, de França, \& Van Praagh, 2016). 


\section{Occlusion and Force}

It is quite common for individuals to clench their jaw when performing a task that involves strength and power. The tension that develops from this action is seen in the face and neck, through production of tension in the masseter muscles, but it can also help to activate core muscles via a Valsalva maneuver(Ebben, Flanagan, \& Jensen, 2008). The presumption is that this creates an ergogenic advantage(Ebben et al., 2008). This jaw positioning during the clench has been correlated with postural control and spinal alignment, and was shown to improve this alignment in children with temporomandibular disorder(Song-Yu et al., 2012). The Valsalva maneuver and this accompanying spinal alignment creates changes in proprioception which may promote improves in performance.

Good posture may directly influence psychosomatic balance control, which suggested that postural stability might be influenced by occlusal status(Song-Yu et al., 2012). The myocentric position, or the position of the mandible that has balanced isotonic muscle contraction during a clench, has produced more stable postural positions when compared to maximal clenching(Bracco, Deregibus, \& Piscetta, 2004). In a study by Song-Yu et al. maximum occlusal pressure had no significant effect on balance(Song-Yu et al., 2012). The postural stability length, or the length of movement to regain balance, tended to be less in a group with a greater number of remaining natural teeth, but significance was not found. Maximum occlusal pressure and the postural stability area, or the area encompassed by the movement of the center of pressure during a standing balance test, also showed a relationship that with greater occlusal force there was less area to regain balance, but again there was no significance(Song-Yu et al., 2012). There have been very few studies examining a relationship between occlusal status and balance, and there needs to be further investigation to produce a causal relationship. 
Jaw clenching during a powerful activity has been shown to increase performance in grip strength tests and counter movement jumping(Hiroshi, 2003). Ebben et al. investigated the effects of jaw clenching on counter movement jumping. The results indicated a $12.1 \%$ improvement in the rate of force development, as compared to a group with non-jaw clenching, and also a $15.8 \%$ increase in rate of force development in a grip strength test(Ebben et al., 2008). Previous reports have indicated that jaw clenching before, as well as during, a power test will improve results. The exact mechanism by which rate of force development are enhanced through jaw clenching is not fully elucidated, but most center on the idea that there is some sensory input to the brain that causes a motor output to the body to enhance force production. The exact pathways are currently the focus of study.

In dentate individuals, jaw-repositioning devices have been shown to improve muscular power(Allen et al., 2018). This differs from strength in that it requires a rapid neuromuscular response. Athletic guards can be purchased over the counter, or made by a dental professional. In a study by Golem et al. the mouth guards were fabricated to be impervious to compression on occlusal pressure(Golem \& Arent, 2015). This resulted in an increase in the occlusal vertical dimension of approximately $3 \mathrm{~mm}($ Golem \& Arent, 2015). The placebo mouth guards, which were boil and bite mouth guards, did not have hard material between the molars, and allowed for compression of the guard under pressure. The results indicated that no significant differences were observed in vertical jump height, or absolute power output. However, there is disagreement in the literature on the subject. It has been shown that the use of a similar jaw repositioning appliance led to improvements in power but not strength(Borg \& Löllgen, 2001). An increase in vertical jump height and anaerobic power output with a jaw repositioning mouth guard has been shown(Golem \& Arent, 2015). Ebben et al. found a $20 \%$ increase in the rate of 
force development in a counter movement jump while clenching on a mouth guard (Ebben et al., 2008). It appears disagreement in literature centers around the selection of mouth guard type, where a custom fabricated mouth guard with a static position is more beneficial than over the counter guards that are compressible by the occlusal force of the clench during function(Allen, Dabbs, Zachary, \& Garner, 2014; Cetin, Keçeci, Erdòan, \& Baydar, 2009; Golem \& Arent, 2015). The studies also do not typically include a dental professional, so no relation to the joint is made, only occlusion into a habitual bite position. Whether this change in jaw position interacts with the whole body via neural connections is still up for debate. The prevailing theory is that the jaw position alters the sensory signals to the brain, which thereby communicates with the motor output neurons to induce the enhanced response(Maurer et al., 2018).

Restoration with complete dentures is recommended for edentulous individuals to aid in their balance and postural control, and also could reverse the deterioration of quickness found in the absence of occlusal support. Whether an individual is completely or partially edentulous, wearing an appropriate prosthesis is significant for both the restoration of mastication, but also for the reconstruction of the occlusal support to stabilize the mandible during physical exertion(Ishijima, Hirai, Koshino, Konishi, \& Yokoyama, 1998). Ishijima et al. stated there is a low possibility that denture wearing effects ground reaction forces, which was in disagreement with an article by Morozumi et al.(Ishijima, Tsutomu \& Hirai, Toshihiro \& Imamura, Tsubura \& Hibino, Kazuto \& Hiranuma, 1991; Ishijima et al., 1998; Morozumi, Yamamoto, Fujiwara, \& Nishiya, 1992).

\section{Conventional and Implant Overdentures}

The ability to restore edentulous individuals has dramatically changed in the near era of implant and digital dentistry. Edentulous individuals used to have conventional dentures 
fabricated for them that relied on the soft tissue, bony architecture, and musculature of the patient to retain and support the prostheses(De Souza E Silva, De Magalhães, \& E Ferreira, 2009). The retention and stability of these prostheses are determining factors in the comfort and successful outcome of an oral rehabilitation. Without these factors, ulcers and mucosal soreness are clinically evident(Nascimento et al., 2017). Due to the instability of this choice of rehabilitation, individuals have a longer adaptation period to perform their daily functions of speech, swallowing, and masticating(Nascimento et al., 2017). This is in large part due to the mandibular complete denture, which unlike the maxillary complete denture, has a difficult time creating a seal to the mucosa allowing for suction to be created. This problem is progressive, as the residual ridge of the mandible will resorb over time becoming thinner and shorter, and the soft tissue becoming more sensitive(Atwood, 1971). The instability and long adaptation periods seen in this treatment modality can also be perceived in the psychological domain, where individuals worry about how they sound, about their prosthesis coming out, and in regards to their self-perception(Albaker, 2013). The results of numerous studies have indicated dissatisfaction with conventional dentures. This dissatisfaction is seen in the quality of life deficits that individuals with conventional removable prostheses have(De Souza E Silva et al., 2009). Lower functional capacity, decreased nutrition, comfort, and psychological factors have all been indicated when compared to a prosthesis that is retained through endosseous dental implants(Assunção et al., 2010).

Dental implants placed to stabilize and retain a mandibular complete denture have been shown to provide significant improvements in many factors that are scored poorly in patients with conventional dentures(Enkling, Saftig, Worni, Mericske-Stern, \& Schimmel, 2017). Improvements in bite force, stability, retention, and comfort have all been indicated when 
switching a patient from a conventional prosthesis to an implant supported one(Van Kampen, Van Der Bilt, Cune, Fontijn-Tekamp, \& Bosman, 2004). An implant overdenture has been shown to significantly increase maximum biting force, approximately three to five times higher than when wearing a conventional prosthesis(Maniewicz et al., 2018). This increase in maximum force has not necessarily shown a correlation to improvements in diet and nutrition(Maniewicz et al., 2018). This is curious, because research has indicated that the implant overdenture has the ability to decrease the amount of cycles of mastication necessary, improved chewing quality of life, and better mastication(Nascimento et al., 2017). In a study by Mueller et al. it was indicated that the chewing efficiency did not change between an implant overdenture group and a recently relined prosthesis(Müller et al., 2013). They theorized that the reline allowed for optimum fit and retention at the time of delivery, before further resorption of the residual ridge influenced these qualities, and this was why the two prosthesis did not show a statistical significance(Müller et al., 2013). It is clear that the introduction of two mandibular implants to convert a conventional prosthesis to an implant supported one positively impacts nearly every facet of the patient's life. 


\section{Materials}

\section{Chapter III: Materials and Methods}

An AMTI strain-gauge force plate (model: SGA6-3, AMTI Inc., Watertown, MA) was utilized for data collection on counter movement jump force. Data were collected at $1050 \mathrm{~Hz}$. The force plate interfaced with an amplifier (gain: 1000; AMTI Inc., Watertown, MA). This amplifier was connected to an analog to digital converter board (USB-6262, National Instruments, Inc., Austin, TX), and ultimately stored and processed on a Dell Latitude E6540 laptop (Dell, Inc., Round Rock, TX).

Data were collected with MatLab (release 2018a, Mathworks, Inc., Natick, MA) software using a custom written coding script. The data were processed on the same laptop using separate custom written code within Matlab. The raw data were processed to generate data for the following variables: Body weight, Mass, Maximum Velocity, Flight time, Take off Velocity, Jump height, Kicking force, Max Push-off force, and Impulse.

A wooden platform was built allowing a foot and a half of landing space on every side of the force platform. This was built and had grip tape placed on it to lower the risk of sliding and falling if individuals landed on the platform. The force platform measured $57 \mathrm{X} 46.3 \times 8.3 \mathrm{~cm}$ and enclosed with this framework. During data collection, 5 participants landed on the platform safely, and through the protocol only one participant had to use the platform to stabilize themselves from falling. All other participants landed on the force plate without issue. No accidents or injuries were recorded in the study.

All of the prostheses were fabricated within the School of Dentistry. All conventional dentures were retained in the mouth without the assistance of any denture adhesive for the duration of data collection. Mandibular overdentures were all retained by two implants utilizing a Locator abutment. 


\section{Variables}

The variables were calculated through the following equations. Participants were asked their age, body weight, and height prior to jumping. Body weight was also assessed on the force plate. Mass was calculated as BW divided by gravity (i.e. $9.81 \mathrm{~m} / \mathrm{s}^{2}$ ). An example of the forces obtained during a counter movement jump is shown in Figure 1.

Figure 1: Ground reaction forces during a counter-movement jump.

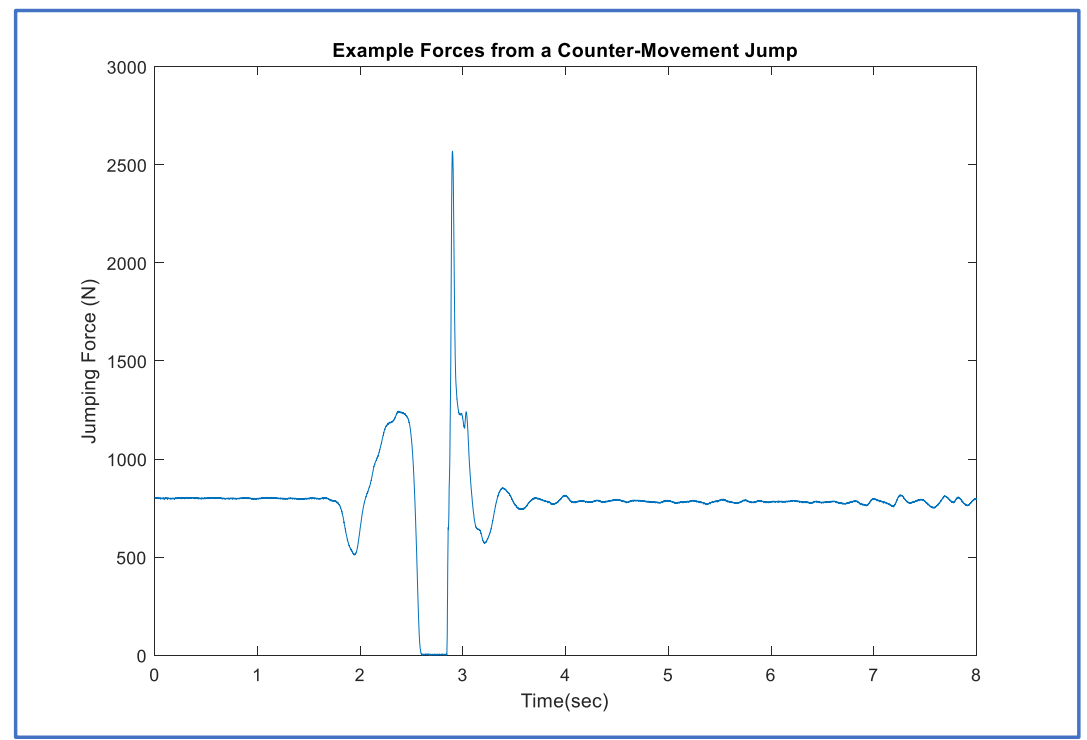

Flight time was obtained by taking the moment they left the force plate, which in the present study was defined as when there was less than $10 \mathrm{~N}$ of force (roughly 2.5 pounds) was exerted on the force plate, to when there was a landing, or more than the $10 \mathrm{~N}$ of force. The amount of $10 \mathrm{~N}$ was chosen due to tremor found in the force plate upon take off, which did not allow it to have a constant zero while the participant was in flight. This threshold of $10 \mathrm{~N}$ is a commonly used figure to determine jump time in the literature(C.P., D.I., \& G.C., 2011).

Take off velocity and jump height were determined using the projectile motion equations of classical mechanics. Specifically, take off velocity (in $\mathrm{m} / \mathrm{s}$ ) was calculated by multiplying gravity $\left(9.81 \mathrm{~m} / \mathrm{s}^{2}\right)$ and time to peak (i.e. half of total flight time) of the jump: 


$$
v_{\text {initial }}=9.81 \frac{\mathrm{m}}{\mathrm{s}^{2}} \times \text { time }_{\text {peak }}
$$

Half of flight time is used because this is the moment of the peak height the participant reached. Jump height was calculated as follows:

$$
\text { jump height }=\frac{1}{2} \times 9.81 \frac{\mathrm{m}}{\mathrm{s}^{2}} \times \text { time }_{\text {peak }}^{2}
$$

Kicking force is defined as the difference in knee bend to max push off forces. Impulse was determined as the area under the force-time curve. Impulse is typically regarded as the sum of net force. The negative impulse is the force going down in the knee bend phase of the countermovement jump. The same amount of force is required to push off and propel the individual off the force plate. By removing the downward knee bend and the equal upward movement, the remaining area under the force curve can be defined as the jump impulse.

\section{Participants and Recruitment}

Participants were gathered from existing patients within the Graduate Prosthodontic clinic at WVU School of Dentistry. This process was completed in four steps. The inclusion criteria were that the individual met the specified dental conditions; conventional denture, implant overdenture, or fully dentate, was over the age of 50, and had the ability to jump. Exclusion criteria included the medical history parameters outlined in the following section, or the inability to jump on their own. The first step was to gather a pool of individuals that met the procedural guidelines of the study. The following dental codes: D5110, D5120, D6111, were selected and searched through our charting system, Axium, to preselect a pool of individuals that had the required treatment done. D5110 is a maxillary complete denture, D5120 is a mandibular complete denture, and D6111 is a mandibular implant overdenture. A cutoff was made to the year of 2013, which at the time of recruitment was approximately five years from the time the 
patient's treatment was completed. This was done to ensure that the prostheses were more likely to still be clinically acceptable as far as retention, vertical dimension of occlusion, and tissue support were concerned. The initial list of maxillary complete dentures had 338 patients. The second step of participant recruitment was to take the list of patients that had the preselected codes mentioned previously, and cross-reference the lists of codes: a maxillary complete denture opposing a complete mandibular denture or a maxillary complete denture opposing a mandibular implant overdenture. Once this was completed the participant pool was narrowed down to 101 individuals: 48 implant over dentures and 53 conventional dentures.

The third step of recruitment was to investigate medical history in the charting system. This was the first time the medical history was reviewed for the participants. Individuals were excluded from the study if they had: a sprain, strain, or fracture of anything in the last 6 months, a joint replacement in the last 6 months, current symptoms or treatment of vertigo, nerve disorders (Parkinson's, MS,etc), currently pregnant. Participants were required the ability to execute five consecutive jumps. The participant pool was narrowed to a total of 58 individuals, 33 implant overdentures and 25 conventional dentures that qualified for the study from the Axium medical history charting.

The final step of recruit involved contacting the individual via phone call. The Axium charting system listed the contact phone number for the individuals and this was utilized to call. Calls were made from the Suncrest Towncenter Dental Clinic phone system. A sample of the recruitment statement has been included. If individuals were willing to participate with the study, an attempt was first made to schedule the visit with a corresponding treatment visit for them, but if they were not actively being treated at the clinic, they were free to make a time during normal business hours. Individuals that were not willing to participate were crossed off 
the master list that had been generated. Ultimately, 24 of the 33 implant overdenture and 20 of the 25 conventional denture individuals were never able to be reached or refused to participate. This resulted in a final nine implant overdenture patients and five conventional denture patients that qualified and agreed to attend the data collection visit for the study.

Recently treated patients in the Graduate Prosthodontic clinic were selected as dentate patients. The 25 most recent patients treated were asked and 15 agreed to attend the data collection visit. Dentate participants were required to meet the same exclusion criteria as the edentulous subjects and were required to have at least first molar occlusion bilaterally.

Participants were instructed to wear comfortable clothing for jumping, and secure shoes such as sneakers.

\section{Procedures}

Participants were met at the Health Science Center School of Dentistry reception area. Upon meeting, participants were taken to the Human Performance Lab (HPL), room 8607 on the $8^{\text {th }}$ floor of the Health Science Center South building. All data collection was completed in this lab. The computer system utilized to collect, process, and house the data was kept locked in this room for the duration of the study, and was not connected to any internet source.

Once arriving in the HPL, participants were shown the force plate and platform. The informed consent was completed (Appendix B), and copied prior to data collection. Participants were shown what a proper countermovement jump movement was for the purposes of this study. This movement was defined as standing on the force platform, once instructed to jump, to knee bend downward and have an upward arm swing as they went through the jump. Participants were instructed to complete five test jumps at this point to familiarize themselves with the position and surroundings on the force plate and to serve as a warm up. 
Dentate individuals were instructed to either clench their teeth together during the jump or jump with their mouth open and teeth apart. These situations simulated the occlusal pressure and no occlusal pressure conditions in the other two subject groups. Edentulous individuals were instructed to clench their teeth together, and for the no occlusal pressure they were asked to remove their dentures. Individuals were instructed not to clench together while their dentures were taken out. The dental professional, for the extent of the no occlusal pressure data collection, handled dentures. No alterations were made to the prostheses during this time. The order of the conditions (occlusal pressure or not) was randomized as to not bias the data by having fatigued individuals participating in the same phase of data collection. Dentures were returned to the patient and ensured that they could be appropriately placed back in. There were no negative outcomes for the edentulous individuals in relation to their dentures during this study.

Five jumps were asked of the participants for each data set. Once the data collection program in Matlab was started, approximately two seconds passed before the participants were instructed to jump. Upon landing approximately twenty seconds elapsed before the laptop was able to collect and process the data. This protocol was repeated for a total of five jumps. Once the data set was completed, subjects were provided a minimum of five minutes of rest before moving on to the second condition. At the five minute mark participants were asked if they were ready to begin, or if they needed to wait longer. Once ready, participants completed the second data set using exactly the same methods as the first set. Visual confirmation was obtained for each jump that the participants had either occlusal pressure or not. Two hundred and ninety jumps were completed in the course of data collection. Eight jumps had to be excluded due to a timing error that lead to inability to record a proper force curve (i.e. subject jumped before the computer started collecting data and the beginning of the jump was missed). 


\section{Statistical Analysis}

Statistical analyses were performed with SPSS v25.0 software (IBM, Inc., Armonk, NY).

For each of the demographic and dependent variables, common measures of dispersion (e.g. mean, standard deviation, minimum, maximum, and 95\% confidence intervals) were determined. Subject demographics (age, height, mass) were compared between groups using a one-factor ANOVA. Group was the independent variable $(\alpha=0.05)$. If significance was found between groups, a Tukey post-hoc test was performed to determine which group was significantly different from which other group in the analysis $(\alpha=0.05)$.

Subsequently, a two-factor (group x condition) ANOVA was performed to determine significance on the lower extremity performance data for each of the dependent variables $(\alpha=0.05)$. Group had three levels: dentate, implant, and conventional dentures. Condition had two levels: high occlusal pressure and no occlusal pressure. The dependent variables were as follows: bodyweight, mass, flight time, take-off velocity, jump height, maximum kicking force, maximum push-off force, and jump impulse. If significance was found between groups, a Tukey post-hoc test was performed $(\alpha=0.05)$. 


\section{Results}

\section{Chapter IV: Results}

The demographic data from the jump analyses can be seen in Table 1. Note that there was no significance found for age or mass among the participants (Table 2). The dentate group was the youngest at an average age of 60.3 years, then the conventional denture group at 62.5 years, and the implant overdenture group at 66 years old. The mass of the participants was also found to not be significant, with the spectrum going implant, conventional, dentate with 71.75 $\mathrm{kg}, 80.34 \mathrm{~kg}$, and $85.84 \mathrm{~kg}$ respectively. While height was found to be significant among the groups, it is not a strong indicator of force generation.

Table 1: Demographics

\begin{tabular}{|l|l|r|r|r|r|}
\hline \multicolumn{2}{|c}{} & \multicolumn{2}{|l|}{$\begin{array}{l}\text { Std. } \\
\text { Deviation }\end{array}$} & Std Error \\
\hline \multirow{3}{*}{ Age (yrs) } & Implant & 6 & 66.0 & 7.6 & 3.1 \\
\cline { 2 - 6 } & Conventional & 8 & 62.5 & 10.5 & 3.7 \\
\cline { 2 - 6 } & Dentate & 15 & 60.3 & 7.1 & 1.8 \\
\cline { 2 - 6 } & Total & 29 & 62.1 & 0.2 & 1.5 \\
\hline Height(cm) & Implant & 6 & 164.2 & 7.9 & 3.2 \\
\cline { 2 - 6 } & Conventional & 8 & 170.5 & 9.1 & 3.2 \\
\cline { 2 - 6 } & Dentate & 15 & 177.9 & 7.6 & 1.9 \\
\cline { 2 - 6 } & Total & 29 & 173.0 & 9.6 & 1.8 \\
\hline \multirow{5}{*}{ Mass(kg) } & Implant & 6 & 71.8 & 15.3 & 6.3 \\
\cline { 2 - 6 } & Conventional & 8 & 80.3 & 15.7 & 5.5 \\
\cline { 2 - 6 } & Dentate & 15 & 85.8 & 11.2 & 2.9 \\
\cline { 2 - 6 } & Total & 29 & 81.4 & 14.0 & 2.6 \\
\hline
\end{tabular}


Table 2: Demographics Group Significance

\begin{tabular}{|l|c|}
\hline \multicolumn{2}{|c|}{ ANOVA } \\
\hline & Sig between groups \\
\hline Age & 0.370 \\
\hline Height $(\mathrm{cm})$ & 0.004 \\
\hline Mass $(\mathrm{kg})$ & 0.109 \\
\hline
\end{tabular}

A one-way ANOVA concluded that there was no statistical significance between the conditions of occlusal pressure and no occlusal pressure for any of the ground reaction force variables measured. The one-way ANOVA was also completed for the force variables identified in this study. Post Hoc analyses utilizing a Tukey test was completed. The results for the individual force variables can be seen in Tables 4-10. Flight time, jump height, take off velocity, max kicking force, max push off force, and jump impulse were all found to be significant between the three groups. Maximum velocity was the one force variable not to be found significant between all three groups, but was found to be significant for the dentate group compared to the two edentulous groups. A post-hoc power analysis indicated that with sufficient sample size a significance could be found for the force variables and occlusal pressure condition.

The tables depict the results of the individual force variables. No significance was found between the with and without conditions, therefore, the significance was found between the groups of conventional, implant, and dentate. The significance is only found from the total values of each group. In the following charts, one can see the mean flight time in seconds, mean jump height in meters, mean take off velocity in $\mathrm{m} / \mathrm{s}$, mean maximum kicking force in $\mathrm{N}$, maximum kicking force $\mathrm{N}$, maximum push off force in $\mathrm{N}$, jump impulse, and maximum velocity 
in $\mathrm{m} / \mathrm{s}$. The mean values for with and without conditions, along with the standard deviations are also included in the tables.

Table 3: Flight Time

\begin{tabular}{|l|l|l|r|l|}
\hline \multicolumn{5}{|c|}{ Flight Time } \\
\hline \multirow{3}{*}{ Group } & Condition & $\begin{array}{l}\text { Mean } \\
\text { (seconds) }\end{array}$ & $\begin{array}{l}\text { Std } \\
\text { Deviation }\end{array}$ & \multirow{2}{*}{ Significance } \\
\hline \multirow{5}{*}{ Implant } & Total & 0.233 & 0.076 & $<0.0001$ \\
\cline { 2 - 4 } & With & 0.232 & 0.075 & \\
\cline { 2 - 4 } & Without & 0.234 & 0.079 & \\
\cline { 2 - 4 } & Total & 0.274 & 0.084 & \multirow{2}{*}{$<0.0001$} \\
\cline { 2 - 4 } & With & 0.274 & 0.089 & \\
\cline { 2 - 4 } & Without & 0.273 & 0.080 & \\
\cline { 2 - 4 } & Total & 0.367 & 0.078 & \multirow{2}{*}{$<0.0001$} \\
\cline { 2 - 4 } & With & 0.362 & 0.077 & \\
\cline { 2 - 4 } & Without & 0.372 & 0.080 & \\
\hline
\end{tabular}

Table 4: Jump Height

\begin{tabular}{|c|c|c|c|c|}
\hline \multicolumn{5}{|c|}{ Jump Height } \\
\hline Group & Condition & $\begin{array}{l}\text { Mean } \\
(\mathrm{m})\end{array}$ & Std Deviation & Significance \\
\hline \multirow[t]{3}{*}{ Conventional } & Total & 0.074 & 0.052 & \multirow[t]{3}{*}{$<0.0001$} \\
\hline & With & 0.073 & 0.051 & \\
\hline & Without & 0.075 & 0.053 & \\
\hline \multirow[t]{3}{*}{ Implant } & Total & 0.100 & 0.062 & \multirow[t]{3}{*}{$<0.0001$} \\
\hline & With & 0.102 & 0.068 & \\
\hline & Without & 0.100 & 0.058 & \\
\hline \multirow[t]{3}{*}{ Dentate } & Total & 0.173 & 0.073 & \multirow[t]{3}{*}{$<0.0001$} \\
\hline & With & 0.167 & 0.072 & \\
\hline & Without & 0.178 & 0.074 & \\
\hline
\end{tabular}


Table 5: Take Off Velocity

\begin{tabular}{|c|c|c|c|c|}
\hline \multicolumn{5}{|c|}{ Take Off Velocity } \\
\hline Group & Condition & $\begin{array}{l}\text { Mean } \\
(\mathrm{m} / \mathrm{s})\end{array}$ & $\begin{array}{l}\text { Std } \\
\text { Deviation }\end{array}$ & Significance \\
\hline \multirow[t]{3}{*}{ Conventional } & Total & 1.14 & 0.375 & \multirow[t]{3}{*}{$<0.0001$} \\
\hline & With & 1.14 & 0.367 & \\
\hline & Without & 1.14 & 0.388 & \\
\hline \multirow[t]{3}{*}{ Implant } & Total & 1.34 & 0.410 & \multirow[t]{3}{*}{$<0.0001$} \\
\hline & With & 1.35 & 0.435 & \\
\hline & Without & 1.34 & 0.390 & \\
\hline \multirow[t]{3}{*}{ Dentate } & Total & 1.80 & 0.384 & \multirow[t]{3}{*}{$<0.0001$} \\
\hline & With & 1.77 & 0.375 & \\
\hline & Without & 1.83 & 0.392 & \\
\hline
\end{tabular}

Table 6: Maximum Kicking Force

\begin{tabular}{|c|c|c|c|c|}
\hline \multicolumn{5}{|c|}{ Maximum Kicking Force } \\
\hline Group & Condition & $\begin{array}{l}\text { Mean } \\
(\mathrm{N})\end{array}$ & $\begin{array}{l}\text { Std } \\
\text { Deviation }\end{array}$ & Significance \\
\hline \multirow[t]{3}{*}{ Conventional } & Total & 1023.86 & 267.92 & \multirow[t]{3}{*}{$<0.0001$} \\
\hline & With & 1024.24 & 271.64 & \\
\hline & Without & 1023.48 & 268.91 & \\
\hline \multirow[t]{3}{*}{ Implant } & Total & 1183.04 & 315.23 & \multirow[t]{3}{*}{$<0.0001$} \\
\hline & With & 1187.73 & 324.71 & \\
\hline & Without & 1178.34 & 309.64 & \\
\hline \multirow[t]{3}{*}{ Dentate } & Total & 1512.48 & 340.12 & \multirow[t]{3}{*}{$<0.0001$} \\
\hline & With & 1462.72 & 346.29 & \\
\hline & Without & 1557.59 & 330.26 & \\
\hline
\end{tabular}


Table 7: Maximum Push Off

\begin{tabular}{|l|l|l|l|l|}
\hline \multicolumn{5}{|c|}{ Max Push Off Force } \\
\hline \multirow{4}{*}{ Group } & Condition & $\begin{array}{l}\text { Mean } \\
(\mathrm{N})\end{array}$ & $\begin{array}{l}\text { Std } \\
\text { Deviation }\end{array}$ & \multirow{2}{*}{ Significance } \\
\hline Conventional & Total & 1457.17 & 305.74 & $<0.0001$ \\
\cline { 2 - 4 } & With & 1464.90 & 315.89 & \\
\cline { 2 - 4 } & Without & 1449.69 & 300.82 & \\
\hline Implant & Total & 1715.05 & 393.80 & \multirow{2}{*}{$<0.0001$} \\
\cline { 2 - 4 } & With & 1728.83 & 402.70 & \\
\cline { 2 - 4 } & Without & 1701.27 & 389.45 & \\
\cline { 2 - 4 } & Total & 1982.70 & 313.61 & \multirow{2}{*}{$<0.0001$} \\
\cline { 2 - 4 } & With & 1935.31 & 304.46 & \\
\cline { 2 - 4 } & Without & 2025.67 & 317.60 & \\
\hline
\end{tabular}

Table 8: Jump Impulse

\begin{tabular}{|c|c|c|c|c|}
\hline \multicolumn{5}{|c|}{ Jump Impulse } \\
\hline Group & Condition & $\begin{array}{l}\text { Mean } \\
\text { (units??) }\end{array}$ & $\begin{array}{l}\text { Std } \\
\text { Deviation }\end{array}$ & Significance \\
\hline \multirow[t]{3}{*}{ Conventional } & Total & 0.975 & 0.426 & \multirow[t]{3}{*}{$<0.0001$} \\
\hline & With & 0.966 & 0.407 & \\
\hline & Without & 0.983 & 0.451 & \\
\hline \multirow[t]{3}{*}{ Implant } & Total & 1.163 & 0.489 & \multirow[t]{3}{*}{$<0.0001$} \\
\hline & With & 1.163 & 0.547 & \\
\hline & Without & 1.163 & 0.430 & \\
\hline \multirow[t]{3}{*}{ Dentate } & Total & 1.694 & 0.435 & \multirow[t]{3}{*}{$<0.0001$} \\
\hline & With & 1.678 & 0.442 & \\
\hline & Without & 1.709 & 0.432 & \\
\hline
\end{tabular}


Table 9: Maximum Velocity

\begin{tabular}{|l|l|l|r|r|}
\hline \multicolumn{5}{|c|}{ Max Velocity } \\
\hline \multirow{3}{*}{ Group } & Condition & $\begin{array}{l}\text { Mean } \\
(\mathrm{m} / \mathrm{s})\end{array}$ & $\begin{array}{l}\text { Std } \\
\text { Deviation }\end{array}$ & Significance \\
\hline \multirow{5}{*}{ Implant } & Total & 1.320 & 0.368 & 0.145 \\
\cline { 2 - 4 } & With & 1.307 & 0.354 & \\
\cline { 2 - 4 } & Without & 1.333 & 0.387 & \\
\hline \multirow{3}{*}{ Dentate } & Total & 1.453 & 0.440 & \multirow{2}{*}{0.145} \\
\cline { 2 - 4 } & With & 1.453 & 0.492 & \\
\cline { 2 - 4 } & Without & 1.453 & 0.387 & \\
\cline { 2 - 4 } & Total & 1.908 & 0.402 & \multirow{2}{*}{$<0.0001$} \\
\cline { 2 - 4 } & With & 1.896 & 0.412 & \\
\cline { 2 - 4 } & Without & 1.919 & 0.395 & \\
\hline
\end{tabular}




\section{Chapter V: Discussion}

The purpose of this investigation was to identify differences in force variables between edentulous, implant, and dentate groups. Edentulous individuals were restored with conventional dentures, while the implant group consisted of individuals with a mandibular two-implant overdenture. The primary aim of this investigation revealed a significant difference between these oral rehabilitation methods and markers of overall physical strength. Surprisingly, while not statistically significant with our sample size, the oldest group of participants in the implant group were on par with the younger completely edentulous group. This is of interest because as stated earlier, function and strength decrease with age, yet this group demonstrated no difference to a younger population of completely edentulous people.

This study found significant difference in all force variables amongst the edentulous and dentate groups, demonstrating a clear difference in the physical capacitance in these sample populations. Of all the variables evaluated only maximum velocity did not show a significance between the three groups. The results of this study indicate there is a relationship between different edentulous rehabilitations and dentate individuals with regards to general physical strength. Individuals with implant overdentures were better able to generate force in the chosen variables of this study compared to individuals restored with conventional dentures. This finding may have a great bearing on clinicians when determining treatment options for individuals. Being able to gain a holistic benefit for these individuals could possibly increase their ability to function more independently, decrease injury risk, and have an overall quality of life improvement. While several studies have demonstrated the psychosocial and masticatory quality of life improvements inherent in restoration with a 2 implant overdenture, this study demonstrates a clear impact on makers of general strength and health(Enkling et al., 2017; Thomason et al., 2012). While this study only explored restoration of mandibular overdentures, 
the strength of the significance found in this study inspires further investigation into whether more implants or more fixed rehabilitations could possibly lead to greater restoration of physical strength similar to the completely dentate patient. The cause for this correlation between implant therapy and increased variables of force is not known at this time. The findings of this investigation are unique within the literature, and demonstrate a clear significance between the groups. These parameters have not been the subject of analysis to this extent before and provide a new avenue for exploration in the effects of masticatory restoration on systemic health and strength.

The secondary aim of the investigation was to compare the presence and absence of occlusal pressure (clenching) on physical performance, which demonstrated no significant differences within or amongst the groups. These findings are in disagreement with Ishijima et al. which investigated maximum jump height (Ishijima et al., 1998) but its important to note that the force plate used in our study is capable of far greater measurements with regards to jump performance. Ishijima's study also suffered from a small sample size, and only investigated conventional dentures. The current variables of force generation were not found to be significant in a study by Ebben et al. (Ebben et al., 2008), but they found an increase in rate of force development(Ebben et al., 2008). This variable was not within the scope of the present study. Rate of force development in a conventional versus implant prosthesis should be elucidated in further research. Limitations of this study include the limited sample size. A larger sample size would have possibly yielded additional significance, specifically between the presence and absence of occlusal pressure. Usage of an accelerometer could also allow further data to be acquired, like the rate of force development. 
Interestingly, there was no significant differences found when comparing age or mass of the three groups. All participants were within the same decade, which is important when comparing force generation and considering fall risk. This also meant that the findings of this study did not have to be adjusted for in relation to the subject demographics. It should be noted though that while no differences were found amongst age of the groups, the 2 implant overdenture group did consist of the oldest participants in this study yet they clearly outperformed the completely edentulous group. This leads to the possibility that older 2 implant overdenture patients may perform comparable to much younger completely edentulous patients which would be an interesting finding with regards to geriatric health but further studies would be required to elucidate this. Height was found to be significant but is not of principal interest for the variables considered.

Edentulous studies show that the restoration of an individual with a prosthesis improves their balance and postural control(Nobili \& Adversi, 1996; Tardieu et al., 2009; Morozumi et al., 1992). There is disagreement in the literature whether occlusal support in edentulous individuals provides a benefit in generation of force and ground reaction forces. The findings of the present study indicate that while there is no relationship between occlusal pressure and lower body force generation; there is however, a relationship between the types of oral rehabilitation that a person receives and there ability to generate force. The role that dental implants play in systemic health and strength have not been investigated, but there are two prevailing theories. The first is the role of nutrition. Implants have not been shown to improve nutrition in comparison to conventional dentures, but there is still not conclusive data to completely rule out a benefit(Wiens \& Priebe, 2014;Albaker, 2013;Yamazaki, Martiniuk, Irie, Sokejima, \& Lee, 2016). In the absence of proper nutrition, it is known that the body will show functional deficits. 
If the presence of implants allows for proper and enhanced nutrition, then the reversal of these deficits could prove to show improvements in force generation, thus this should be studied further. The second prevailing theory is the role of inflammation. The presence of past and current inflammation that accompanies the loss of teeth has been shown to have total body effects(Visser et al., 2002). This inflammation generally comes from the presence of periodontal disease, but can also accompany tooth decay(Visser et al., 2002). Research indicates that the presence of inflammation has the ability to shrink sarcomere size and diminish muscular output(Runge, Rittweger, Russo, Schiessl, \& Felsenberg, 2004). Exercise and training was not a factor that was considered in the present study, but would be of interest in future studies. If the impact of inflammation and edentulism could be reversed through exercise and strength training, it would prove a major benefit for these populations. It is important to note though that whole body health is multifactorial so nutrition and inflammation may represent only two factors in a complex system.

Other research indicates that occlusal stability can also play a role in balance and stability. This postural control may play a role in the ability to maximally generate force, by not having to overcome poor mechanics or positioning that accompanies poor posture(Golem \& Arent, 2015). A study of this kind would require a multi-camera system involving body markers but could be an important factor that has not been fully investigated yet.

The current project has opened several areas of potential future research. Firstly, different forms of implant restoration should be utilized to show any significance between restoration type and implant number, as only a mandibular two implant overdenture was utilized. As more implants are introduced, the role of nutrition could be better studied as individuals ability to masticate deficient foods are improved. Secondly, edentulous individuals should be 
put through exercise training to see if improvements in the tested force variables can be seen. This could possibly show a connection between the role of inflammation in reduction in muscle power and if it is reversible. Thirdly, a prospective study that tested individuals at the three different stages: prior to extraction, after healing and fabrication of conventional dentures, and after placement and pickup of implants for an overdenture. This would allow researchers to better understand the loss of function for an individual through the course of treatment. Findings from these studies could establish a correlation between the process of tooth loss, implant therapy, and functional capacity. This is of great significance as the population of elderly individuals increases. 


\section{Chapter VI: Summary and Conclusion}

\section{Summary}

The present study investigated the effect different oral conditions had on lower body force generation. Edentulous, implant, and dentate groups were evaluated. The dentate individuals had the highest values for the tested force variables, then implant overdenture, and finally conventional denture. Occlusal pressure was also tested as a variable for force generation between the groups. A force plate system was utilized to collect ground reaction forces to quantify the ability of these individuals to generate force in a vertical direction. There was no significance between presence and absence of occlusal pressure. These findings for the significance between the groups is novel, and the lack of significance between occlusal pressure and not is consistent with most currently accepted findings.

\section{Conclusion}

1. Individuals possessing an implant overdenture are better able to generate lower body force then individuals possessing a conventional denture.

2. Dentate individuals are better able to generate lower body force when compared to edentulous individuals.

3. Occlusal pressure has no effect on lower body force generation. 


\section{References:}

Ajwani, S., Mattila, K. J., Närhi, T. O., Tilvis, R. S., \& Ainamo, A. (2003). Oral health status, Creactive protein and mortality--a 10 year follow-up study. Gerodontology. https://doi.org/10.1111/j.1741-2358.2003.00032.x

Albaker, A. M. (2013). The oral health-related quality of life in edentulous patients treated with Conventional complete dentures. Gerodontology, 30(1), 61-66. https://doi.org/10.1111/j.1741-2358.2012.00645.x

Allen, C. R., Dabbs, N. C., Zachary, C. S., \& Garner, J. C. (2014). The acute effect of a commercial bite-aligning mouthpiece on strength and power in recreationally trained men. Journal of Strength and Conditioning Research. https://doi.org/10.1519/JSC.0b013e3182a95250

Allen, C. R., Fu, Y. C., Cazas-Moreno, V., Valliant, M. W., Gdovin, J. R., Williams, C. C., \& Garner, J. C. (2018). Effects of jaw clenching and jaw alignment mouthpiece use on force production during vertical jump and isometric clean pull. Journal of Strength and Conditioning Research, 32(1), 237-243. https://doi.org/10.1519/JSC.0000000000002172

Assunção, W. G., Barão, V. A. R., Delben, J. A., Gomes, É. A., \& Tabata, L. F. (2010). A comparison of patient satisfaction between treatment with conventional complete dentures and overdentures in the elderly: A literature review. Gerodontology. https://doi.org/10.1111/j.1741-2358.2009.00299.x

Atwood, D. A. (1971). Reduction of residual ridges: A major oral disease entity. The Journal of Prosthetic Dentistry. https://doi.org/10.1016/0022-3913(71)90069-2

Avlund, K., Holm-Pedersen, P., \& Schroll, M. (2001). Functional ability and oral health among older people: A longitudinal study from age 75 to 80. Journal of the American Geriatrics Society, 49(7), 954-962. https://doi.org/10.1046/j.1532-5415.2001.49187.x 
Borg, G., \& Löllgen, H. (2001). Borg's perceived exertion and pain scales. Deutsche Zeitschrift Fur Sportmedizin.

Bracco, P., Deregibus, A., \& Piscetta, R. (2004). Effects of different jaw relations on postural stability in human subjects. Neuroscience Letters. https://doi.org/10.1016/j.neulet.2003.11.055

Brown, D. W. (2009). Complete edentulism prior to the age of 65 years is associated with allcause mortality. Journal of Public Health Dentistry, 69(4), 260-266. https://doi.org/10.1111/j.1752-7325.2009.00132.x

Bui, H. T., Farinas, M. I., Fortin, A. M., Comtois, A. S., \& Leone, M. (2015). Comparison and analysis of three different methods to evaluate vertical jump height. Clinical Physiology and Functional Imaging, 35(3), 203-209. https://doi.org/10.1111/cpf.12148

C.P., M., D.I., L., \& G.C., G. (2011). The role of rate of force development on vertical jump performance. Journal of Strength and Conditioning Research.

CDC. (2017). Heart Disease Facts. https://doi.org/10.15844/pedneurbriefs-29-11-7

Cetin, C., Keçeci, A. D., Erdòan, A., \& Baydar, M. L. (2009). Influence of custom-made mouth guards on strength, speed and anaerobic performance of taekwondo athletes. Dental Traumatology. https://doi.org/10.1111/j.1600-9657.2009.00780.x

Chauncey, H. H., Muench, M. E., Kapur, K. K., \& Wayler, A. H. (1984). The effect of the loss of teeth on diet and nutrition. Int Dent $J$.

Corby, P., Newman, A. B., Rubin, S. M., Harris, T. B., Rooks, R., Kritchevsky, S. B., ... Lee, J. S. (2018). Edentulism and nutritional status in a biracial sample of well-functioning, community-dwelling elderly: the Health, Aging, and Body Composition Study. The American Journal of Clinical Nutrition, 79(2), 295-302. 
https://doi.org/10.1093/ajen/79.2.295

De Souza E Silva, M. E., De Magalhães, C. S., \& E Ferreira, E. F. (2009). Complete removable prostheses from expectation to (dis)satisfaction. Gerodontology. https://doi.org/10.1111/j.1741-2358.2008.00243.x

Eagles, A. N., Sayers, M. G. L., Bousson, M., \& Lovell, D. I. (2015). Current Methodologies and Implications of Phase Identification of the Vertical Jump: A Systematic Review and Metaanalysis. Sports Medicine, 45(9), 1311-1323. https://doi.org/10.1007/s40279-015-0350-7

Ebben, W. P., Flanagan, E. P., \& Jensen, R. L. (2008). Jaw clenching results in concurrent activation potentiation during the countermovement jump. Journal of Strength and Conditioning Research. https://doi.org/10.1519/JSC.0b013e3181875117

Elsyad, M. A., \& Khairallah, A. S. (2017). Chewing efficiency and maximum bite force with different attachment systems of implant overdentures: a crossover study. Clinical Oral Implants Research. https://doi.org/10.1111/clr.12861

Enkling, N., Saftig, M., Worni, A., Mericske-Stern, R., \& Schimmel, M. (2017). Chewing efficiency, bite force and oral health-related quality of life with narrow diameter implants a prospective clinical study: results after one year. Clinical Oral Implants Research. https://doi.org/10.1111/clr.12822

Ensrud, K. E., Ewing, S. K., Cawthon, P. M., Fink, H. A., Taylor, B. C., Cauley, J. A., ... Cummings, S. R. (2009). A comparison of frailty indexes for the prediction of falls, disability, fractures, and mortality in older men. Journal of the American Geriatrics Society. https://doi.org/10.1111/j.1532-5415.2009.02137.x

Felton, D. A. (2009). Edentulism and comorbid factors. Journal of Prosthodontics, 18(2), 88-96. https://doi.org/10.1111/j.1532-849X.2009.00437.x 
Fonseca, R. M. C., de França, N. M., \& Van Praagh, E. (2016). Relationship between Indicators of Fitness and Bone Density in Adolescent Brazilian Children. Pediatric Exercise Science. https://doi.org/10.1123/pes.20.1.40

Forsman, P., Tietäväinen, A., Wallin, A., \& Hæggström, E. (2008). Modeling balance control during sustained waking allows posturographic sleepiness testing. Journal of Biomechanics. https://doi.org/10.1016/j.jbiomech.2008.07.003

Frost, H. M. (2004). A 2003 update of bone physiology and Wolff s law for clinicians. Angle Orthodontist.

Golem, D. L., \& Arent, S. M. (2015). Effects of over-the-counter jaw-repositioning mouth guards on dynamic balance, flexibility, agility, strength, and power in college-aged male athletes. Journal of Strength and Conditioning Research, 29(2), 500-512. https://doi.org/10.1519/JSC.0000000000000641

Greenspan, S. L., Myers, E. R., Kiel, D. P., Parker, R. A., Hayes, W. C., \& Resnick, N. M. (n.d.). Function : Risk Factors for Hip Fracture in Frail Nursing Home Elderly. 9343(13), 539545.

Guralnik, J. M., Ferrucci, L., Simonsick, E. M., Salive, M. E., \& Wallace, R. B. (1995). Lowerextremity function in persons over the age of 70 years as a predictor of subsequent disability. The New England Journal of Medicine. https://doi.org/10.1017/CBO9781107415324.004

Hämäläinen, P., Rantanen, T., Keskinen, M., \& Meurman, J. H. (2004). Oral health status and change in handgrip strength over a 5-year period in 80-year-old people. Gerodontology, 21(3), 155-160. https://doi.org/10.1111/j.1741-2358.2004.00022.x

Hämäläinen, P., Suominen, H., Keskinen, M., \& Meurman, J. H. (2004). Oral health and 
reduction in respiratory capacity in a cohort of community-dwelling elderly people: a population-based 5-year follow-up study. Gerodontology, 21(4), 209-215. https://doi.org/10.1111/j.1741-2358.2004.00029.x

Hardcastle, S. A., Gregson, C. L., Rittweger, J., Crabtree, N., Ward, K., \& Tobias, J. H. (2014). Jump power and force have distinct associations with cortical bone parameters: Findings from a population enriched by individuals with high bone mass. Journal of Clinical Endocrinology and Metabolism. https://doi.org/10.1210/jc.2013-2837

Harman, E. A., Rosenstein, M. T., Frykman, P. N., \& Rosenstein, R. M. (1990). The effects of arms and countermovement on vertical jumping. Medicine and Science in Sports and Exercise. https://doi.org/10.1249/00005768-199012000-00015

Heitmann, B. L., \& Gamborg, M. (2008). Remaining teeth, cardiovascular morbidity and death among adult Danes. Preventive Medicine. https://doi.org/10.1016/j.ypmed.2008.04.007

Hewit, J., Cronin, J., \& Hume, P. (2012). Multidirectional leg asymmetry assessment in sport. Strength and Conditioning Journal. https://doi.org/10.1519/SSC.0b013e31823e83db

Hiroshi, C. (2003). Relation between teeth clenching and grip force production characteristics. Kokubyo Gakkai Zasshi. The Journal of the Stomatological Society, Japan. https://doi.org/10.5357/koubyou.70.82

Holm-Pedersen, P., Schultz-Larsen, K., Christiansen, N., \& Avlund, K. (2008). Tooth loss and subsequent disability and mortality in old age. Journal of the American Geriatrics Society. https://doi.org/10.1111/j.1532-5415.2007.01602.x

Hubley, C. L., \& Wells, R. P. (1983). A work-energy approach to determine individual joint contributions to vertical jump performance. European Journal of Applied Physiology and Occupational Physiology. https://doi.org/10.1007/BF00422163 
Hung, H.-C., Joshipura, K. J., Colditz, G., Manson, J. E., Rimm, E. B., Speizer, F. E., \& Willett, W. C. (2004). The association between tooth loss and coronary heart disease in men and women. Journal of Public Health Dentistry.

Ishijima, Tsutomu \& Hirai, Toshihiro \& Imamura, Tsubura \& Hibino, Kazuto \& Hiranuma, K. (1991). The frequency of clenching during physical exertion. Journal of Japanese Prosthodontic Society, (35), 193-199.

Ishijima, T., Hirai, T., Koshino, H., Konishi, Y., \& Yokoyama, Y. (1998). The relationship between occlusal support and physical exercise ability. Journal of Oral Rehabilitation, 25(6), 468-471. https://doi.org/10.1046/j.1365-2842.1998.00254.x

Jette, A. M., Feldman, H. A., \& Douglass, C. (1993). Oral Disease and Physical Disability in Community-Dwelling Older Persons. Journal of the American Geriatrics Society. https://doi.org/10.1111/j.1532-5415.1993.tb06459.x

Joshipura, K. J., Willett, W. C., \& Douglass, C. W. (1996). The impact of edentulousness: On food and nutrient intake. Journal of the American Dental Association. https://doi.org/10.14219/jada.archive.1996.0237

Ju, Y. I., Sone, T., Ohnaru, K., Tanaka, K., Yamaguchi, H., \& Fukunaga, M. (2014). Effects of different types of jump impact on trabecular bone mass and microarchitecture in growing rats. PLoS ONE. https://doi.org/10.1371/journal.pone.0107953

Kibele, A. (1998). Possibilities and limitations in the biomechanical analysis of countermovement jumps: A methodological study. Journal of Applied Biomechanics. https://doi.org/10.1123/jab.14.1.105

Kimura, M., Watanabe, M., Tanimoto, Y., Kusabiraki, T., Komiyama, M., Hayashida, I., \& Kono, K. (2013). Occlusal support including that from artificial teeth as an indicator for 
health promotion among community-dwelling elderly in Japan. Geriatrics and Gerontology International. https://doi.org/10.1111/j.1447-0594.2012.00931.x

Koka, S., Priebe, J., Wermers, R. A., Sems, S. A., \& Viozzi, C. F. (2017). Relationship of Number of Missing Teeth to Hip Fracture in Elderly Patients: A Cohort Pilot Study. Journal of Prosthodontics, 28, 258-263. https://doi.org/10.1111/jopr.12626

Linthorne, N. P. (2002). Analysis of standing vertical jumps using a force platform. American Journal of Physics. https://doi.org/10.1119/1.1397460

Maniewicz, S., Duvernay, E., Srinivasan, M., Perneger, T., Schimmel, M., \& Müller, F. (2018). Effect of implant-supported mandibular overdentures versus reline on masticatory performance and salivary flow rates in very old adults-A randomized clinical trial. Clinical Oral Implants Research. https://doi.org/10.1111/clr.13392

Maurer, C., Heller, S., Sure, J. J., Fuchs, D., Mickel, C., Wanke, E. M., ... Ohlendorf, D. (2018). Strength improvements through occlusal splints? The effects of different lower jaw positions on maximal isometric force production and performance in different jumping types. PLoS ONE, 13(2), 1-17. https://doi.org/10.1371/journal.pone.0193540

Meurman, J. H., Pajukoski, H., Snellman, S., Zeiler, S., \& Sulkava, R. (1997). Oral infections in home-living elderly patients admitted to an acute geriatric ward. Journal of Dental Research. https://doi.org/10.1177/00220345970760060601

Mollaoglu, M. N., \& Alpar, R. (2005). The effect of dental profile on daily functions of the elderly. Clinical Oral Investigations. https://doi.org/10.1007/s00784-005-0307-6

Morozumi, K., Yamamoto, I., Fujiwara, T., \& Nishiya, T. (1992). Effect of Dentures Wearing on Motor Reaction Time and.

Müller, F., Duvernay, E., Loup, A., Vazquez, L., Herrmann, F. R., \& Schimmel, M. (2013). 
Implant-supported mandibular overdentures in very old adults: A randomized controlled trial. Journal of Dental Research. https://doi.org/10.1177/0022034513509630

N'Gom, P. I., \& Woda, A. (2002). Influence of impaired mastication on nutrition. Journal of Prosthetic Dentistry. https://doi.org/10.1067/mpr.2002.123229

Nagi, S. Z. (1976). An epidemiology of disability among adults in the United States. The Milbank Memorial Fund Quarterly. Health and Society.

Nascimento, G. G., Bielemann, A. M., Faot, F., Del Bel Cury, A. A., Schuster, A. J., \& Marcello-Machado, R. M. (2017). How fast can treatment with overdentures improve the masticatory function and OHRQoL of atrophic edentulous patients? A 1-year longitudinal clinical study. Clinical Oral Implants Research, 29(2), 215-226.

https://doi.org/10.1111/clr.13101

Nicol, C., Avela, J., \& Komi, P. V. (2006). The Stretch-Shortening Cycle. Sports Medicine. https://doi.org/10.2165/00007256-200636110-00004

Nobili, A., \& Adversi, R. (1996). Relationship between posture and occlusion: A clinical and experimental investigation. Cranio. https://doi.org/10.1080/08869634.1996.11745978

Nowjack-Raymer, R. E., \& Sheiham, A. (2003). Association of edentulism and diet and nutrition in US adults. Journal of Dental Research, 82(2), 123-126. https://doi.org/10.1177/154405910308200209

Padua, D. A., Arnold, B. L., Perrin, D. H., Gansneder, B. M., Carcia, C. R., \& Granata, K. P. (2006). Fatigue, vertical leg stiffness, and stiffness control strategies in males and females. Journal of Athletic Training.

Papas, A. S., Palmer, C. A., Rounds, M. C., \& Russell, R. M. (1998). The effects of denture status on nutrition. Special Care in Dentistry. https://doi.org/10.1111/j.1754- 
4505.1998.tb01354.x

Payette, H., Roubenoff, R., Jacques, P. F., Dinarello, C. A., Wilson, P. W. F., Abad, L. W., \& Harris, T. (2003). Insulin-like growth factor-1 and interleukin 6 predict sarcopenia in very old community-living men and women: The Framingham heart study. Journal of the American Geriatrics Society. https://doi.org/10.1046/j.1532-5415.2003.51407.x

Polzer, I., Schimmel, M., Müller, F., \& Biffar, R. (2010). Edentulism as part of the general health problems of elderly adults. International Dental Journal. https://doi.org/10.1080/15598608.2016.1268550

Rantanen, T., Avlund, K., Suominen, H., Schroll, M., Frändin, K., \& Pertti, E. (2002). Muscle strength as a predictor of onset of ADL dependence in people aged 75 years. Aging Clinical and Experimental Research.

Rantanen, T., Volpato, S., Ferrucci, L., Heikkinen, E., Fried, L. P., \& Guralnik, J. M. (2003). Handgrip strength and cause-specific and total mortality in older disabled women: Exploring the mechanism. Journal of the American Geriatrics Society. https://doi.org/10.1034/j.1600-0579.2003.00207.x

Rodacki, A. L. F., Fowler, N. E., \& Bennett, S. J. (2002). Vertical jump coordination: Fatigue effects. Medicine and Science in Sports and Exercise, 34(1), 105-116. https://doi.org/10.1097/00005768-200201000-00017

Runge, M., Rittweger, J., Russo, C. R., Schiessl, H., \& Felsenberg, D. (2004). Is muscle power output a key factor in the age-related decline in physical performance? A comparison of muscle cross section, chair-rising test and jumping power. Clinical Physiology and Functional Imaging. https://doi.org/10.1111/j.1475-097X.2004.00567.x

Sargent, D. A. (2018). The Physical Test of a Man. American Physical Education Review. 
https://doi.org/10.1080/23267224.1921.10650486

Schneider, P., Schwab, M., \& Hänscheid, H. (2011). Identification of factors associated with risk of fall using a force platform and power spectrum analysis technique. Journal of Biomechanics, 44(10), 2008-2012. https://doi.org/10.1016/j.jbiomech.2011.05.007

Schwahn, C., Völzke, H., Robinson, D. M., Luedemann, J., Bernhardt, O., Gesch, D., ... Kocher, T. (2004). Periodontal disease, but not edentulism, is independently associated with increased plasma fibrinogen levels. Results from a population-based study. Thrombosis and Haemostasis.

Sheiham, A., Steele, J. G., Marcenes, W., Finch, S., \& Walls, A. W. (1999). The impact of oral health on stated ability to eat certain foods; findings from the National Diet and Nutrition Survey of Older People in Great Britain. Gerodontology. https://doi.org/10.1111/j.17412358.1999.00011.x

Sheiham, A., Steele, J. G., Marcenes, W., Lowe, C., Finch, S., Bates, C. J., .. Walls, A. W. G. (2001). The relationship among dental status, nutrient intake, and nutritional status in older people. Journal of Dental Research. https://doi.org/10.1177/00220345010800020201

Simons, C., \& Bradshaw, E. J. (2016). Do accelerometers mounted on the back provide a good estimate of impact loads in jumping and landing tasks? Sports Biomechanics. https://doi.org/10.1080/14763141.2015.1123765

Slade, G. D., Akinkugbe, A. A., \& Sanders, A. E. (2014). Projections of U.S. edentulism prevalence following 5 decades of decline. Journal of Dental Research, 93(10), 959-965. https://doi.org/10.1177/0022034514546165

Song-Yu, X., Rodis, O. M. M., Ogata, S., Can-Hu, J., Nishimura, M., \& Matsumura, S. (2012). Postural stability and occlusal status among Japanese elderly. Gerodontology, 29(2), 988- 
997. https://doi.org/10.1111/j.1741-2358.2011.00596.x

Tada, A., Watanabe, T., Yokoe, H., Hanada, N., \& Tanzawa, H. (2003). Relationship between the number of remaining teeth and physical activity in community-dwelling elderly. Archives of Gerontology and Geriatrics. https://doi.org/10.1016/S0167-4943(03)00026-8

Tardieu, C., Dumitrescu, M., Giraudeau, A., Blanc, J. L., Cheynet, F., \& Borel, L. (2009). Dental occlusion and postural control in adults. Neuroscience Letters. https://doi.org/10.1016/j.neulet.2008.12.005

Taylor, B. C., Schreiner, P. J., Stone, K. L., Fink, H. A., Cummings, S. R., Nevitt, M. C., ... Ensrud, K. E. (2004). Long-term prediction of incident hip fracture risk in elderly white women: Study of osteoporotic fractures. Journal of the American Geriatrics Society, 52(9), 1479-1486. https://doi.org/10.1111/j.1532-5415.2004.52410.x

Thomason, J. M., Kelly, S. A. M., Bendkowski, A., \& Ellis, J. S. (2012). Two implant retained overdentures - A review of the literature supporting the McGill and York consensus statements. Journal of Dentistry. https://doi.org/10.1016/j.jdent.2011.08.017

Tran, J., Netto, K., Aisbett, B., \& Gastin, P. (2005). Validation of Accelerometer Data for Measuring Impacts During Jumping and Landing Tasks. ANZMAC 2005: Broadening the Boundaries, Conference Proceedings. https://doi.org/10.1675/1524-4695(2008)31

Van Kampen, F. M. C., Van Der Bilt, A., Cune, M. S., Fontijn-Tekamp, F. A., \& Bosman, F. (2004). Masticatory function with implant-supported overdentures. Journal of Dental Research. https://doi.org/10.1177/154405910408300910

Vanezis, A., \& Lees, A. (2005). A biomechanical analysis of good and poor performers of the vertical jump. Ergonomics, 48(11-14), 1594-1603. https://doi.org/10.1080/00140130500101262 
Verbrugge, L. M., \& Jette, A. M. (1994). The disablement process. Social Science and Medicine. https://doi.org/10.1016/0277-9536(94)90294-1

Visser, M., Pahor, M., Taaffe, D. R., Goodpaster, B. H., Simonsick, E. M., Newman, A. B., ... Harris, T. B. (2002). Relationship of interleukin-6 and tumor necrosis factor- $\alpha$ with muscle mass and muscle strength in elderly men and women: The health ABC study. Journals of Gerontology - Series A Biological Sciences and Medical Sciences. https://doi.org/10.1093/gerona/57.5.M326

Wang, L. I., Lin, D. C., \& Huang, C. (2004). Age effect on jumping techniques and lower limb stiffness during vertical jump. Research in Sports Medicine, 12(3), 209-219. https://doi.org/10.1080/15438620490497549

Wiens, J. P., \& Priebe, J. W. (2014). Occlusal stability. Dental Clinics of North America, 58(1), 19-43. https://doi.org/10.1016/j.cden.2013.09.014

Yamaga, T., Yoshihara, A., Ando, Y., Yoshitake, Y., Kimura, Y., Shimada, M., ... Miyazaki, H. (2002). Relationship between dental occlusion and physical fitness in an elderly population. Journals of Gerontology - Series A Biological Sciences and Medical Sciences. https://doi.org/10.1093/gerona/57.9.M616

Yamazaki, T., Martiniuk, A. L. C., Irie, K., Sokejima, S., \& Lee, C. M. Y. (2016). Does a mandibular overdenture improve nutrient intake and markers of nutritional status better than conventional complete denture? A systematic review and meta-analysis. BMJ Open. https://doi.org/10.1136/bmjopen-2016-011799 


\title{
Curriculum Vitae:
}

671 Kenwood Place, Morgantown, WV |304-276-8531 | MTHDDS16@ gmail.com

Objective

My career goals include:

Completion of a Maxillofacial Prosthodontic Fellowship

Completion of American College of Prosthodontics Board Certification

Faculty Position at WVU School of Dentistry as the Maxillofacial Prosthodontist

Re-establish the Maxillofacial Clinic at WVU Hospital

\section{Education}

\author{
B.S. | May 2012 | West Virginia University \\ Major: Exercise Physiology \\ Minor: Biology, Philosophy
}

D.D.S. | May 2016 | West Virginia University School of dentistry

Currently Licensed in the State of West Virginia

Eligible for Licensure in all States Accepting CDCA Board Examination

\section{CE Attended}

2018

All-on-four and Zygomatic Implant Placement

2017

Restorative Dentistry and Material Options

Advanced Complete Dentures

Mixed Media Dental Solutions Using IPS EMAX

2016

Creativity with New Ceramics

Posterior Composites: A Rapid, Simplified, and Predictable Placement Technique and

Metal Free Crowns

Emergency Medicine in Dentistry

Advanced Complete Dentures

Mixed Media Dental Solutions Using IPS EMAX

2015

Drug Diversion and Best Practice Prescribing Controlled Substances

Esthetics and Function in Implant Dentistry: Treatment Planning, Surgical, and

Restorative Aspects

Advanced Complete Dentures

Mixed Media Dental Solutions Using IPS EMAX

Professional Meetings Attended

2018

American College of Prosthodontics - Baltimore, Maryland

2017 
American College of Prosthodontics - San Francisco, CA

Digital Dentistry Symposium - Chicago, IL

American Academy of Fixed Prosthodontics - Chicago, IL

Chicago Dental Society Midwinter Meeting - Chicago, IL

LMT Lab Day - Chicago, IL

2016

American College of Prosthodontics - San Diego, CA

WV Dental Association Annual Meeting - White Sulfur Springs, WV

2015

WV Dental Association Annual Meeting - White Sulfur Springs, WV

2014

American College of Prosthodontics - New Orleans- LA

\section{Professional Experience}

WVU School of Dentistry Prosthodontic Resident

Resident Teaching Responsibility:

Implantology: Fall 2018

Clinical Supervisor: Fall 2018-Spring 2019

Implantology: Fall 2017

Occlusion: Summer 2017

Implantology: Fall 2016

Guest Lecturer in Graduate Physiology Course

Clinical Correlations for Dentistry: Fall 2018

Clinical Correlations for Dentistry: Fall 2017

Guest Lecturer in Dental Pathology Course

Role of the Maxillofacial Prosthodontist: Spring 2018

WVU School of Dentistry Clinical Faculty

Complete Denture and Removable Partial Denture Preclinical Courses

May 2016-August 2016

\section{Awards and Societies}

Awards:

2018

WVU Health Science Center "Rising Star Award"

Awarded for excellence in research and work towards completion of program

2016

Southeastern Academy of Prosthodontics Award for Prosthodontic Excellence

Awarded for Excellence in Prosthodontic Care during Dental School

WVU School of Dentistry Research Award

Awarded for Research Project on Intra-Oral Calcifications in Appalachian

Population 
WVU School of Dentistry Scholarship for Excellence in Patient Care Awarded for Excellence in Patient Management and Care

2014

WVU School of Dentistry Scholarship for Cleft Palate and Maxillofacial Prosthetics Awarded for Involvement in Cleft Palate Clinic

2012-2016

WVU School of Dentistry Class President

Societies:

2017-Present

American Academy of Maxillofacial Prosthetics

2014-Present

American College of Prosthodontics

2012-Present

American Dental Association 


\section{Appendix A}

Word of mouth recruitment Sample:

Hello (Patients name),

My name is Dr Matthew Harper. I am a second year resident at the WVU Graduate

Prosthodontic clinic. I am calling you regarding an opportunity to be included in my Master's research study. The study is to examine if there is a difference for people with implants or not when they jump. This is an important study because if a correlation could be found, it could lead to more emphasis on placing implants, and open up future research regarding what implant configurations work best.

The study would require you to come to the Health Science Center building, attached to the hospital. The PI of the study, Dr Jean McCrory, has a lab where the study will take place. All that will be asked of you is that you complete ten (10) jumps, five (5) with your dentures in and five (5) with them out. I will be there for the process and ensure your dentures are handled with care. The time required should not exceed thirty (30) minutes start to finish. We have an informed consent that we will go over prior to the jumping. You were selected by running a review of our clinics completed procedures in the last six (6) years. There are some factors they may exclude you from the study, and those include: Movement disorders, neurological diseases/disorders (such as Parkinson's), a joint replacement in the lower body in the last six (6) months, and strain/sprain/fracture in the last six (6) months, symptoms of vertigo, or being currently pregnant. If none of those apply to you, you would qualify to participate.

I am unable to supply any financial compensation for this study, so my goal was to have you attend the data collection the same day you have your hygiene visit here at the school, so that you are only making one trip to Morgantown. All of your data will be kept confidential and if published you will be completely de-identified.

I thank you for your time. 


\section{Appendix B}

Research Consent: See following pages due to formatting. 
Only Minimal Risk

Consent Information and HIPAA Form

Principal Investigator

Department

Protocol Number

Study Title

Co-Investigator(s)

Sponsor (if any)
Dr Jean McCrory

School of Dentistry

1803021012

Comparison of Vertical Force Generation in Conventional Complete Dentures and Implant Retained Overdentures

Dr Matthew Harper, Dr Matthew Bryington

None

\section{Contact Persons}

In the event you experience any side effects or injury related to this research, you should contact Dr. Matthew Harper at (304) 276-8531. (After hours contact: Dr. Matthew Harper at (304)276-8531). If you have any questions, concerns, or complaints about this research, you can contact Dr. Jean McCrory (304) 293-0442 or Dr. Matthew Harper at (304) 276-8531

For information regarding your rights as a research subject, to discuss problems, concerns, or suggestions related to the research, to obtain information or offer input about the research, contact the Office of Research Integrity and Compliance at (304) 293-7073.

In addition if you would like to discuss problems, concerns, have suggestions related to research, or would like to offer input about the research, contact the Office of Research Integrity and Compliance at 304-293-7073.

\section{Introduction}

You, , have been asked to participate in this research study, which has been

explained to you by . This study is being conducted by Dr. Jean McCrory in the

Department of Exercise Physiology and Dr. Matthew Harper in the Department of Prosthodontics at West

Virginia University.

Purpose(s) of the Study

The purpose of this study is to identify a correlation between occlusal support and force production by jumping. Occlusal support will be evaluated by having three groups of participants; individuals with no teeth and complete dentures, and individuals with no teeth but with implants placed to retain complete dentures, and dentate individuals (those containing their natural teeth). This is important because various studies have been published identifying decreases in quality of life for patients with no teeth. An area of importance in studies involving the elderly population is that of stability and falling. Many of these studies use force production in the lower body as a marker of increased ability to resist falling and have heightened stability. The aim of the research is to see if there is a significant difference in the production of force between these groups, because if so, there could be further research done to identify what methods of oral rehabilitation can improve the quality of life of these patient populations.

Description of Procedures
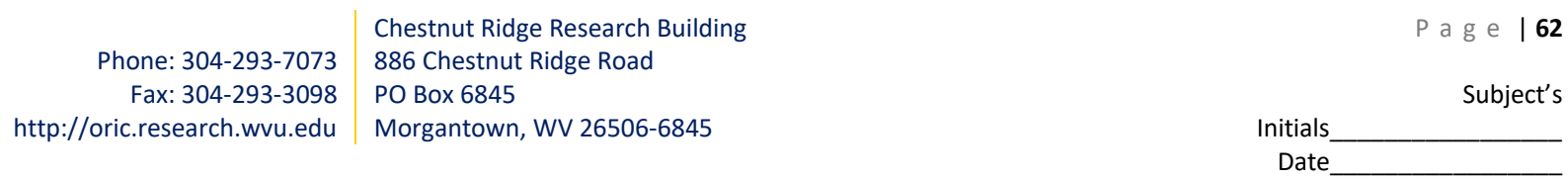

\section{Approved: 15-Feb-2019 Expires: 14-Feb-2020 Number: 180301012}


This study involves jumping in place five times, twice. The first time will be with your dentures placed in your mouth, and the second set of jumps will take place with the dentures out of your mouth. The dentate individuals will jump with teeth together, and a second set with their mouth open to simulate the teeth out situation for the edentulous groups. You will jump on a force plate, or a device that measures the forces under your feet, so we can see how hard you push off when you jump. We will also place a small cube-shaped device called an accelerometer on one of your shins using an elastic wrap so that we can see how fast you accelerate when you jump. Dr. Matthew Harper will be present for the jumping to ensure the dentures are handled appropriately. This will take approximately thirty (30) minutes to explain the procedure, fill out this informed consent, and complete the required jumps.

Discomforts

There are no known or expected risks from participating in this study, except for the mild frustration associated with answering the questions.

\section{Alternatives}

You do not have to participate in this study.

\section{Benefits}

You may not receive any direct benefit from this study. The knowledge gained from this study may eventually benefit others.

\section{Financial Considerations}

No payment is to be rendered to participants.

Confidentiality

Any information about you that is obtained as a result of your participation in this research will be kept as confidential as legally possible. Your research records and test results, just like hospital records, may be subpoenaed by court order or may be inspected by the study sponsor or federal regulatory authorities without your additional consent.

Audiotapes or videotapes will be kept locked up and will be destroyed as soon as possible after the research is finished.

In any publications that result from this research, neither your name nor any information from which you might be identified will be published without your consent.

\section{HIPAA}

We know that information about you and your health is private. We are dedicated to protecting the privacy of that information. Because of this promise, we must get your written authorization (permission) before we may use or disclose your protected health information or share it with others for research purposes.

You can decide to sign or not to sign this authorization section. However, if you choose not to sign this authorization, you will not be able to take part in the research study. Whatever choice you make about this research study will not have an effect on your access to medical care.

Persons/Organizations Providing the Information

Patient/West Virginia University School of Dentistry

\begin{tabular}{r|lr} 
& Chestnut Ridge Research Building & P a g e | 63 \\
Phone: 304-293-7073 & 886 Chestnut Ridge Road & Subject's \\
Fax: 304-293-3098 & PO Box 6845 & Initials___ \\
http://oric.research.wvu.edu & Morgantown, WV 26506-6845 & Date__
\end{tabular}

\section{Approved: 15-Feb-2019 Expires: 14-Feb-2020 Number: 180301012}




\section{Persons/Organizations Receiving the Information}

- $\quad$ The research site(s) carrying out this study. This includes UHA or UHA Affiliated, WVU, WVU Hospitals. It also includes each site's research staff and medical staff

- $\quad$ Health care providers who provide services to you as part of this research study.

- $\quad$ Laboratories and other people and groups that look into your health information as part of this study in agreement with the study protocol.

- $\quad$ The United State Department of Health and Human Services (which includes the National Institutes of Health (NIH), Food and Drug Administration (FDA)) and other groups that have the right to use the information as required by law.

- $\quad$ The members and staff of any Institutional Review Board (IRB) that oversees this research study.

- West Virginia University Office of Research Integrity and Compliance and Office of Sponsored Programs.

The Following Information Will Be Used

Information from your existing medical records and new information about you that is created or collected during the study such as: history and physicals, clinic visit notes, demographic data, and study forms.

The Information is Being Disclosed for the Following Reasons

- $\quad$ Review of your data for quality assurance purposes

- $\quad$ Publication of study results (without identifying you)

- $\quad$ Other research purposes such as reviewing the safety or effectiveness of the study drug and other products or therapies; conducting performance reviews of the study drug; evaluating other products or therapies for patients; developing a better understanding of disease; improving the design of future clinical trials You May Cancel this Authorization at Any Time by Writing to the Principal Investigator PI Name and Full Contact Information

If you cancel this authorization, any information that was collected already for this study cannot be withdrawn. Once information is disclosed, according to this authorization, the recipient may redisclose it and then the information may no longer be protected by federal regulations.

You have a right to see and make copies of your medical records. You will not be able to see or copy your records related to the study until the sponsor has completed all work related to the study. At that time you may ask to see the study doctor's files related to your participation in the study and have the study doctor correct any information about you that is wrong.

This authorization will expire at the end of the study unless you cancel it before that time (or has a specific expiration date).

Voluntary Participation

\begin{tabular}{r|l} 
& Chestnut Ridge Research Building \\
Phone: 304-293-7073 & 886 Chestnut Ridge Road \\
Fax: 304-293-3098 & PO Box 6845 \\
http://oric.research.wvu.edu & Morgantown, WV 26506-6845
\end{tabular}

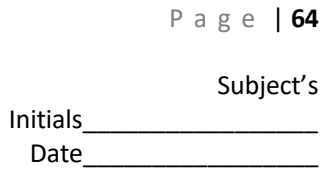

\section{Approved: 15-Feb-2019 Expires: 14-Feb-2020 Number: 180301012}


Participation in this study is voluntary. You are free to withdraw your consent to participate in this study at any time.

Refusal to participate or withdrawal will not affect dental treatment and will involve no penalty to you. Refusal to participate or withdrawal will not affect your future care at West Virginia University.

In the event new information becomes available that may affect your willingness to participate in this study, this information will be given to you so that you can make an informed decision about whether or not to continue your participation.

You have been given the opportunity to ask questions about the research, and you have received answers concerning areas you did not understand.

Upon signing this form, you will receive a copy.

I willingly consent to participate in this research.

Signatures

Signature of Subject

Printed Name

Date

Time

The participant has had the opportunity to have questions addressed. The participant willingly agrees to be in the study.

Signature of Investigator or Co-Investigator

Printed Name

Date

Time

Phone: 304-293-7073

Fax: 304-293-3098

http://oric.research.wvu.edu
Chestnut Ridge Research Building

886 Chestnut Ridge Road

PO Box 6845

Morgantown, WV 26506-6845
$P$ a g e $\mid 65$

Subject's

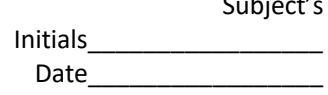

\section{Approved: 15-Feb-2019 Expires: 14-Feb-2020 Number: 180301012}

